九州大学学術情報リポジトリ

Kyushu University Institutional Repository

\title{
Dynamic Modeling and Validation of a Carbon Dioxide Heat Pump System
}

Ko, Jaedeok

Department of Energy and Environmental Engineering, Interdisciplinary Graduate School of Engineering Science, Kyushu University

Takata, Nobuo

Department of Energy and Environmental Engineering, Interdisciplinary Graduate School of Engineering Science, Kyushu University

Thu, Kyaw

Department of Energy and Environmental Engineering, Interdisciplinary Graduate School of Engineering Science, Kyushu University

Miyazak, Takahiko

Department of Energy and Environmental Engineering, Interdisciplinary Graduate School of Engineering Science, Kyushu University

https://doi.org/10.5109/4055215

出版情報：Evergreen. 7 (2)，pp.172-194，2020-06. 九州大学グリーンテクノロジー研究教育センター バージョン：

権利関係 : 


\title{
Dynamic Modeling and Validation of a Carbon Dioxide Heat Pump System
}

\author{
Jaedeok Ko ${ }^{1, *}$, Nobuo Takata ${ }^{1}$, Kyaw Thu' ${ }^{1,2}$, Takahiko Miyazaki ${ }^{1,2}$ \\ ${ }^{1}$ Department of Energy and Environmental Engineering, Interdisciplinary Graduate School of Engineering Sciences, \\ Kyushu University, 6-1 Kasuga-koen, Kasuga-shi, Fukuoka, 816-8580, Japan \\ ${ }^{2}$ Thermal Science and Engineering Division, International Institute of Carbon-Neutral Energy Research ( $\left.\mathrm{I}^{2} \mathrm{CNER}\right)$, \\ Kyushu University, 744 Motooka, Nishi-ku, Fukuoka 819-0395, Japan
}

*Author to whom correspondence should be addressed: E-mail: ko.jaedeok.980@s.kyushu-u.ac.jp

(Received March 4, 2020; Revised April 14, 2020; accepted April 14, 2020).

\begin{abstract}
The objective of the present manuscript is to develop a dynamic model to simulate the transient performance of a heat pump system that utilizes environmental-friendly refrigerant, Carbon Dioxide (R-744). Exploiting the high customizability of the modeling tools supporting acausal, equation-based, and object-oriented modeling approach, a dynamic model for a transcritical heat pump system was developed. The model was validated with the experimental results with particular attention to the refrigerant mass flow rate, cooling/heating capacity, compressor power, and the coefficient of performance.
\end{abstract}

Keywords: dynamic modeling; validation; carbon dioxide (R-744); heat pump system;

\section{Introduction}

Smart society and connected devices can be considered as a new technology era. With the forthcoming $5 \mathrm{G}$ technology, ubiquitous smart-devices offer tremendous opportunities for energy optimization and efficiency gain. One of the main features of the smart society is operating the connected devices which smartly controlled based on real-time demand ${ }^{1}$. From this perspective, it is important to understand the transient behaviors of the devices while heating, ventilation, air-conditioning, and refrigeration (HVAC\&R) systems constitute a dominating share of energy usage. Thus, chillers and heat pumps can no longer be considered as the devices that operate at steady-state.

Table 1. Transient simulation tools.

\begin{tabular}{|c|c|}
\hline Tool & Modeling approach \\
\hline TRNSYS ${ }^{2)}$ & $\begin{array}{l}\text { Causal, non-equation-based, non- } \\
\text { object-oriented }\end{array}$ \\
\hline Modelica3)/Dymola ${ }^{4)}$ & $\begin{array}{l}\text { Acausal, equation-based, object- } \\
\text { oriented }\end{array}$ \\
\hline MATLAB/Simulink ${ }^{5)}$ & $\begin{array}{l}\text { Causal, non-equation-based, } \\
\text { object-oriented }\end{array}$ \\
\hline MATLAB/Simscape $e^{6)}$ & $\begin{array}{l}\text { Acausal, equation-based, object- } \\
\text { oriented }\end{array}$ \\
\hline
\end{tabular}

The preliminary design of a smart-controlled thermal system is one of the critical phases in its development. In most cases, the initial design is developed through numerical and analytical treatments. Modeling and simulation offer huge advantages as compared to the experimental procedure. However, developing a transient simulation model for a complex system is often a timeconsuming and effort-demanding process. Knowledge of building up a network connection and integration of all physical parameters in submodels is essential. Additionally, a proper ordinary differential equation (ODE) solver needs to be selected to avoid some numerical hiccups during simulations.

These challenging tasks have been resolved by the help of simulation programming tools that offer different paradigms of modeling approaches; therefore, engineers could put more effort into physical modeling. Transient simulation tools, which have been frequently employed for the research on thermal systems, are categorized in Table 1. According to the previous studies which compared the acausal, equation-based, and objectoriented tool and the causal, non-equation-based, and nonobject-oriented tool ${ }^{7,8), 9)}$, it was revealed that the former is a more effective method than the latter for creating userdefined models to implement of model components; the latter was cited as burdens to engineers in creating a new component model. Due to the disadvantages of the simulation tools based on the causal and non-equationbased approach as well as with the increasing demands of complex thermal systems, causal and non-equation-based approach modeling tools are often shunned by the industry. This void is filled up by acausal, equation-based, and 
object-oriented modeling tools that offer a multi-physical domain. Modelica, as a well-known and open-source tool, has already passed numerous experimental validations. On the other hand, Simscape has merits in terms of generating fewer equations and it is not only powerful and user-friendly for control purposes but also can provide more flexible and easy ways for users to extend their models into a multi-physical domain by offering an integrated-tool platform ${ }^{10)}$; nevertheless, the reported research works on the modeling and simulation of physical systems using Simscape are considered rare $^{11), 12), 13)}$. Recently, Singh and Sørensen ${ }^{14)}$ developed a dynamic simulation model based on Simscape for an R407C heat pump system. Using the model, they investigated the effects of ambient temperature on the system performance and room temperature. However, the validation was absent.

Meanwhile, Chlorofluorocarbon (CFC) and Hydrochlorofluorocarbon (HCFC) have been dominantly used as the working fluids in the conventional vapor compression systems. However, they are on the phase-out process because of their high ozone-depleting potential (ODP) and global warming potential (GWP). Carbon dioxide (R-744) is one of the promising alternative refrigerants with zero ODP and GWP of one ${ }^{15)}$. R-744 has a low critical temperature of $31.1^{\circ} \mathrm{C}$ so, in most cases, R744 heat pump systems are operated by transcritical cycles. In the transcritical cycle, heat rejection at the highpressure side occurs not by the condensation, but by the gas cooling. During the gas cooling process, refrigerant temperatures and pressures are independent of each other; moreover, near the pseudocritical line, there is a dramatic change in the thermophysical properties of R-744. These facts become challenges for engineers to modeling R-744 systems.

Over the last couple of decades, various researches have been conducted, empirically and numerically, for R-744 heat pump systems to investigate their performance and improve it. To understand the transient behavior of R-744 heat pump systems and their performance, researchers have tried to develop dynamic models. Pfafferott and Schmitz ${ }^{16)}$ developed a library for R-744 refrigeration systems for aircraft in Modelica. By utilizing that library, they developed a simulation model and validated their model with experimental results. Shi et al. ${ }^{17)}$ developed a dynamic model of an R-744 supermarket refrigeration system using Dymola. They compared the simulation results to the field data. Zheng et al. ${ }^{18), 19)}$ developed their dynamic simulation model for an R-744 refrigeration system equipped with an ejector and improved it for a two-stage evaporating system. They validated their model by focusing on the ejector performance and corresponding system behavior. Bush et al. ${ }^{20}$ built up an R-744 transcritical refrigeration system for supermarket applications using the pre-validated component model based on Modelica/Dymola. After the system model was experimentally validated, the system's response was investigated when the system encounters sudden changes in thermal load.

To develop smart HVAC\&R systems based on real-time demands, it is essential to understand the dynamic behaviors of the connected devices. In this perspective, well-validated dynamic models are considered as useful tools for engineers because they enable to investigate the system performance at various operating conditions and to simulate control methods, minimizing the extensive experimental procedures. Several dynamic models for R744 transcritical heat pump systems were reported in the literature, however, when it comes to being compared to conventional system models that are operated by subcritical cycles, transcritical models of R-744 systems are rather limited. The objective of the present study is to develop and simulate the transient behavior of an R-744 transcritical heat pump system. The model meticulously attempts to incorporate the heat transfer mechanisms in the evaporator and the gas cooler as well as detailed models for the compressor and the expansion process. The Simscape simulation environment was adopted utilizing the object-oriented and customizable technique. The dynamic response of the R-744 heat pump system is validated using in-house experimental data.

\section{Methodology}

\subsection{Actual heat pump system}

A schematic of the experimental apparatus is shown in Fig. 1 (a). The apparatus consists of an R-744 heat pump system, a cooling water loop, and a heating water loop. The heat pump consists of a scroll compressor, which is controlled by an inverter, a tube-in-tube type heat exchanger (HX) as a gas cooler, an electronic expansion valve (EEV), and a plate-type $\mathrm{HX}$ as an evaporator. The schematic of the gas cooler and the evaporator are shown in Fig. 1 (b). The gas cooler consists of three inner-tubes and a single outer-tube. The refrigerant flows inside the three inner-tubes while the cooling water flows annular space between the inner-tubes and outer-tube, in countercurrent direction to the refrigerant flow. The evaporator consists of ten channels of the refrigerant flow and eleven channels of the heating water flow. Specification of the mentioned four main components of the heat pump system is summarized in Table 2. An oil separator at the compressor discharge is utilized to rid the effects of lubricant oil circulation. Sight-glasses, at the evaporator inlet and the compressor suction, are to check the refrigerant flow phase. Each water loop consists of a constant temperature water bath, a circulation pump, a gear-type flow meter, and a by-pass valve. 
(a)

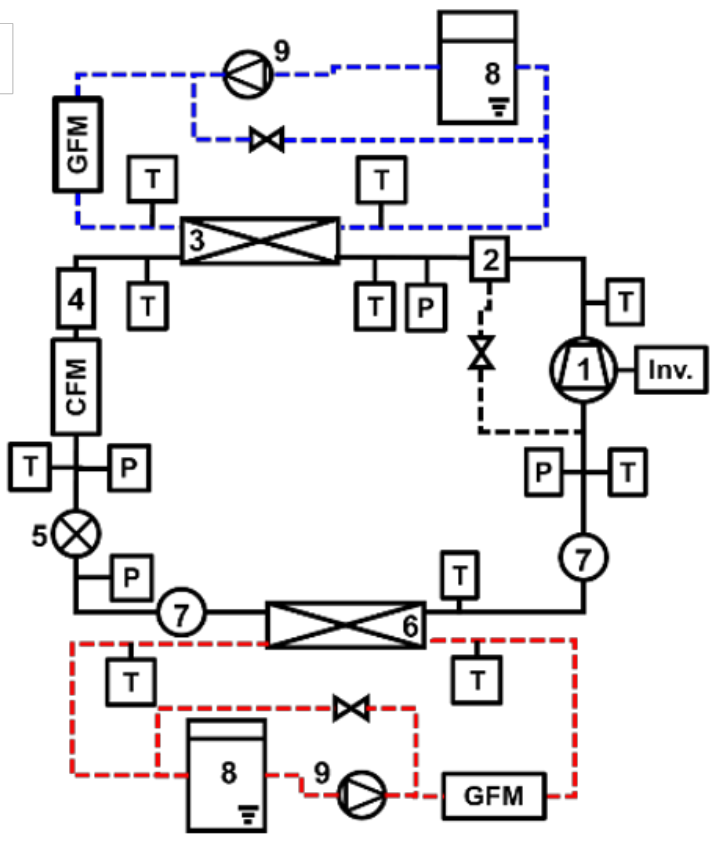

1. Compressor

2. Oil separator

3. Gas cooler

4. Receiver

5. Expansion valve

6. Evaporator

7. Sight glass

8. Water bath

9. Pump

CFM: Coriolis flow meter

GFM: Gear flow meter

$T$ : Temperature sensor

$P$ : Pressure sensor

Inv.: Invertor

$\bowtie$ Valve

R-744 heat pump

---. Oil return

---. Cooling water loop

---. Heating water loop

(b)

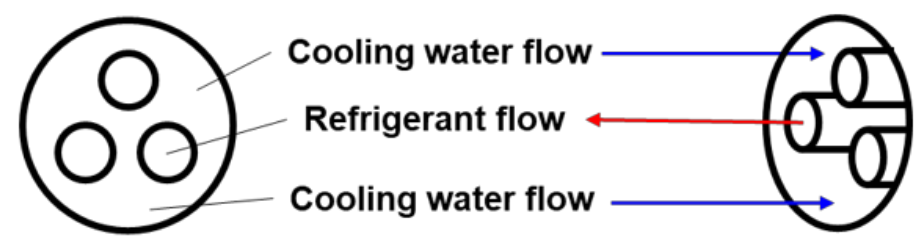

Gas cooler

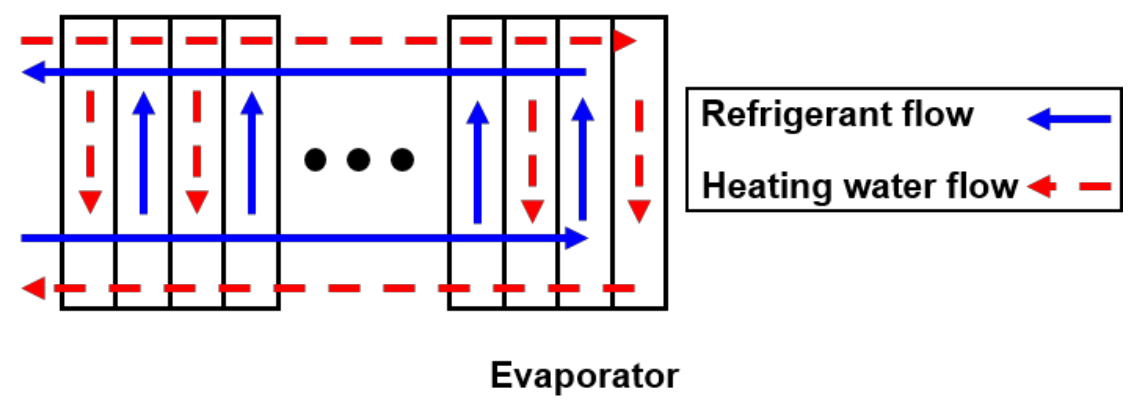

Fig. 1: (a) schematic of experimental apparatus, (b) schematic of the gas cooler and the evaporator.

During the experiments, pressure and temperature of the refrigerant flow were measured at each main component's inlet and outlet by pressure sensors and Ktype thermocouples, respectively. The refrigerant mass flow rate was measured by a Coriolis mass flow meter installed at the inlet of the EEV. Temperatures of the water at the inlet and outlet of each HX were measured by Ktype thermocouples. The water flow rate in each water loop was measured by the gear-type flow meter. The flow was regulated by the by-pass valve. Controlling the water temperature at each $\mathrm{HX}$ inlet was performed by the constant temperature water bath installed in each water loop. In the gas cooler, the refrigerant heat was rejected to the cooling water, while in the evaporator, the heating water heat was absorbed into the refrigerant. The degree of superheating at the compressor suction was adjusted by the opening step of the EEV. Electric signal using a digital panel manually controlled the EEV's opening step to adjust the degree of suction superheating. The rotation speed of the compressor was controlled by the inverter. The compressor and inverter are connected to a power meter. Readings of power and rotation speed were indicated in a display window to check its input power and speed. All the measuring instruments are connected to a data acquisition system. Their readings were recorded every second. The experimental range carried out in the present study is tabulated in Table 3. 
Table 2. Specification of the experimental heat pump.

\begin{tabular}{|c|c|c|c|}
\hline Component & Content & Value or range & Unit \\
\hline \multirow{3}{*}{ Compressor } & Swept volume & 4.0 & $\mathrm{~cm}^{3}$ \\
\hline & Rotation speed range & 30 to 90 & $\mathrm{rev} / \mathrm{s}$ \\
\hline & Diameter of suction and discharge tubes & 6.53 & $\mathrm{~mm}$ \\
\hline \multirow{6}{*}{ Gas cooler } & Inner diameter of the inner tubes & 2.8 & \multirow{4}{*}{$\mathrm{mm}$} \\
\hline & Outer diameter of the inner tubes & 4.4 & \\
\hline & Inner diameter of the outer tube & 14.6 & \\
\hline & Outer diameter of the outer tube & 16.0 & \\
\hline & Tube length & 13.6 & $\mathrm{~m}$ \\
\hline & Overall heat transfer area & 0.578 & $\mathrm{~m}^{2}$ \\
\hline \multirow{5}{*}{ EEV } & Diameter of inlet and outlet tubes & 6.35 & $\mathrm{~mm}$ \\
\hline & Maximum pressure at the inlet & 14 & \multirow{2}{*}{$\mathrm{MPa}$} \\
\hline & Maximum differential pressure & 10 & \\
\hline & Operating temperature range & -30 to 70 & ${ }^{\circ} \mathrm{C}$ \\
\hline & Opening step (close - full open) & 0 to 500 & - \\
\hline \multirow{4}{*}{ Evaporator } & Width & 90 & \multirow{3}{*}{$\mathrm{mm}$} \\
\hline & Depth & 35 & \\
\hline & Height & 434 & \\
\hline & Overall heat transfer area & 0.648 & $\mathrm{~m}^{2}$ \\
\hline
\end{tabular}

Table 3. Experimental range.

\begin{tabular}{|c|c|c|}
\hline Operating parameter & Range & Unit \\
\hline \multicolumn{3}{|l|}{ Gas cooler } \\
\hline Water flow rate & 45 to 145 & $\mathrm{~L} / \mathrm{h}$ \\
\hline Water inlet temperature & 20 to 30 & ${ }^{\circ} \mathrm{C}$ \\
\hline \multicolumn{3}{|l|}{ Evaporator } \\
\hline Water flow rate & 77 to 350 & $\mathrm{~L} / \mathrm{h}$ \\
\hline Water inlet temperature & 15 to 20 & ${ }^{\circ} \mathrm{C}$ \\
\hline Charge & 1.4 to 1.7 & $\mathrm{~kg}$ \\
\hline Refrigerant mass flow rate & 35 to 55 & $\mathrm{~kg} / \mathrm{h}$ \\
\hline Suction pressure & 3.4 to 4.7 & \multirow{2}{*}{$\mathrm{MPa}$} \\
\hline Discharge pressure & 7.8 to 10.5 & \\
\hline Suction superheating & 2 to 20 & \multirow{2}{*}{${ }^{\circ} \mathrm{C}$} \\
\hline Discharge temperature & 70 to 100 & \\
\hline
\end{tabular}

Based on the measured data, the heat transfer rates in the refrigerant-side $\left(\dot{Q}_{r}\right)$ and water-side $\left(\dot{Q}_{w}\right)$ at each $\mathrm{HX}$ were calculated by:

$$
\begin{aligned}
& \dot{Q}_{r}=\dot{m}_{r} \Delta h_{r . i . o} \\
& \dot{Q}_{w}=\dot{V}_{w} \rho_{w . i}\left(\frac{C_{P . w . i}+C_{P . w . o}}{2}\right) \Delta T_{\text {w.i.o }},
\end{aligned}
$$

where $\Delta h_{\text {r.i.o }}, \dot{V}_{w}, \rho_{w . i}, C_{P . w . i}, C_{P . w . o}$, and $\Delta T_{w . i . o}$ represent the refrigerant specific enthalpy difference between the inlet and outlet of the $\mathrm{HX}$, the water flow rate, the water density at the inlet of the $\mathrm{HX}$, the specific heats of water at the inlet and outlet of the HX and the temperature difference of water between at the inlet and outlet of the $\mathrm{HX}$, respectively. All thermodynamic properties of the refrigerant and water were obtained from Lemmon et al. ${ }^{21)}$.

Fig. 2 shows the heat balance test results at each $\mathrm{HX}$ in steady-state conditions. All experimental data is within
$10 \%$ of heat balance error, and $90 \%$ of total data shows a good agreement within a 6\% error. Coefficient of performance (COP) for cooling and heating was assessed by:

$$
\begin{aligned}
& C O P_{c}=\frac{\dot{Q}_{w \cdot e v a p}}{\dot{W}}, \\
& C O P_{h}=\frac{\dot{Q}_{w \cdot g c}}{\dot{W}},
\end{aligned}
$$

where $\dot{Q}_{\text {w.evap }}$ and $\dot{Q}_{w . g c}$ denote the heat transfer rates of the water-side for evaporator and gas cooler, respectively.

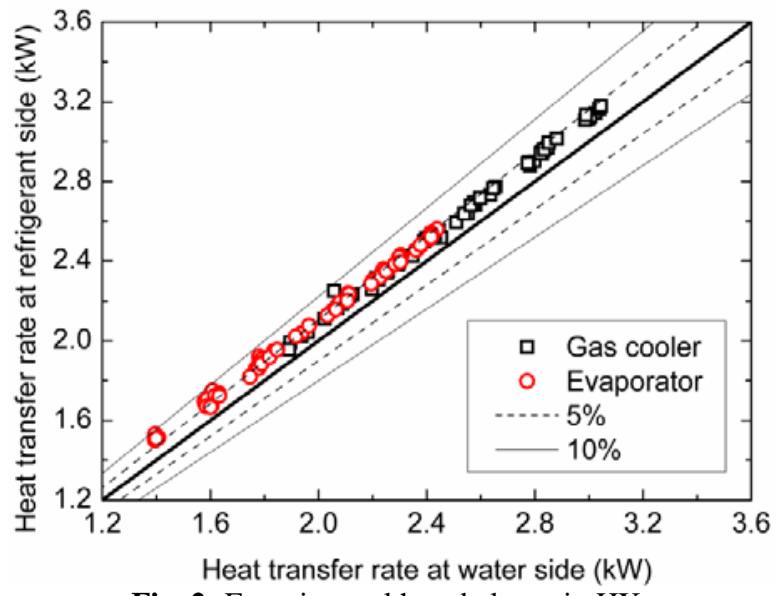

Fig. 2: Experimental heat balance in HXs.

The reduced data, such as heat exchange rate at each HX and COPs, have a relationship with measured data (i.e., independent variables) as follows:

$$
\Psi=f\left(\psi_{1}, \ldots, \psi_{n}\right),
$$


where $\Psi$ and $\psi$ represent the reduced data and the measured data, correspondingly. Uncertainty of the reduced data can be calculated by:

$$
U_{\Psi}=\left(\sum_{i=1}^{n}\left(\frac{\partial}{\partial \psi_{i}} f\left(\psi_{1}, \ldots \psi_{n}\right)\right) U_{\psi_{i}}\right)^{0.5}
$$

where $U_{\Psi}$ and $U_{\psi_{i}}$ represent the uncertainty of the reduced data and the uncertainty of independently measured data, respectively. Uncertainties of measured and reduced data are summarized in Table 4 .

Table 4. Uncertainties of measured and reduced data.

\begin{tabular}{|c|c|c|c|}
\hline Data type & Content & Uncertainty & Unit \\
\hline \multirow{11}{*}{ Measured data } & Temperature & \pm 0.1 & ${ }^{\circ} \mathrm{C}$ \\
\hline & \multicolumn{3}{|l|}{ Pressure } \\
\hline & at the gas cooler inlet & \pm 0.044 & \multirow{4}{*}{$\mathrm{MPa}$} \\
\hline & at the EEV inlet & \pm 0.040 & \\
\hline & at the EEV outlet & \pm 0.015 & \\
\hline & at the suction & \pm 0.017 & \\
\hline & Refrigerant mass flow rate & $\pm 1.08 \%$ of reading & $\mathrm{kg} / \mathrm{h}$ \\
\hline & \multicolumn{3}{|l|}{ Water flow rate } \\
\hline & at the cooling water loop & \multirow{2}{*}{ \pm 1.0} & \multirow{2}{*}{$\mathrm{L} / \mathrm{h}$} \\
\hline & at the heating water loop & & \\
\hline & Compressor power & $\pm(0.1 \%$ of reading +0.002$)$ & $\mathrm{kW}$ \\
\hline \multirow{4}{*}{ Reduced data } & Heating capacity of the gas cooler & $\pm 5.4 \%$ of the value & \multirow{2}{*}{$\mathrm{kW}$} \\
\hline & Cooling capacity of the evaporator & $\pm 5.3 \%$ of the value & \\
\hline & $C O P_{h}$ & $\pm 5.5 \%$ of the value & \\
\hline & $C O P_{C}$ & $\pm 5.4 \%$ of the value & \\
\hline
\end{tabular}

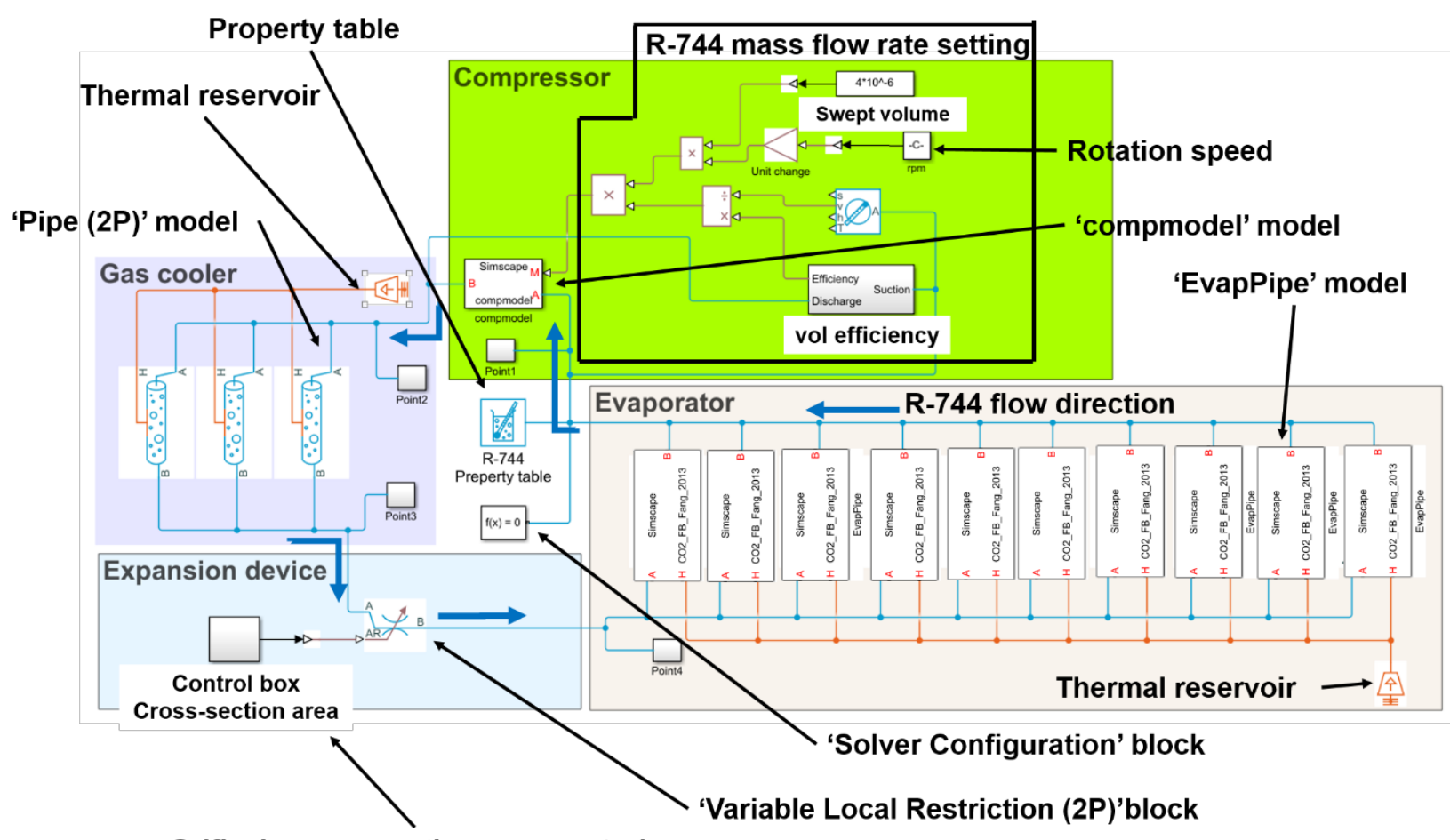

Orifice's cross-section area control

(a) Model diagram 


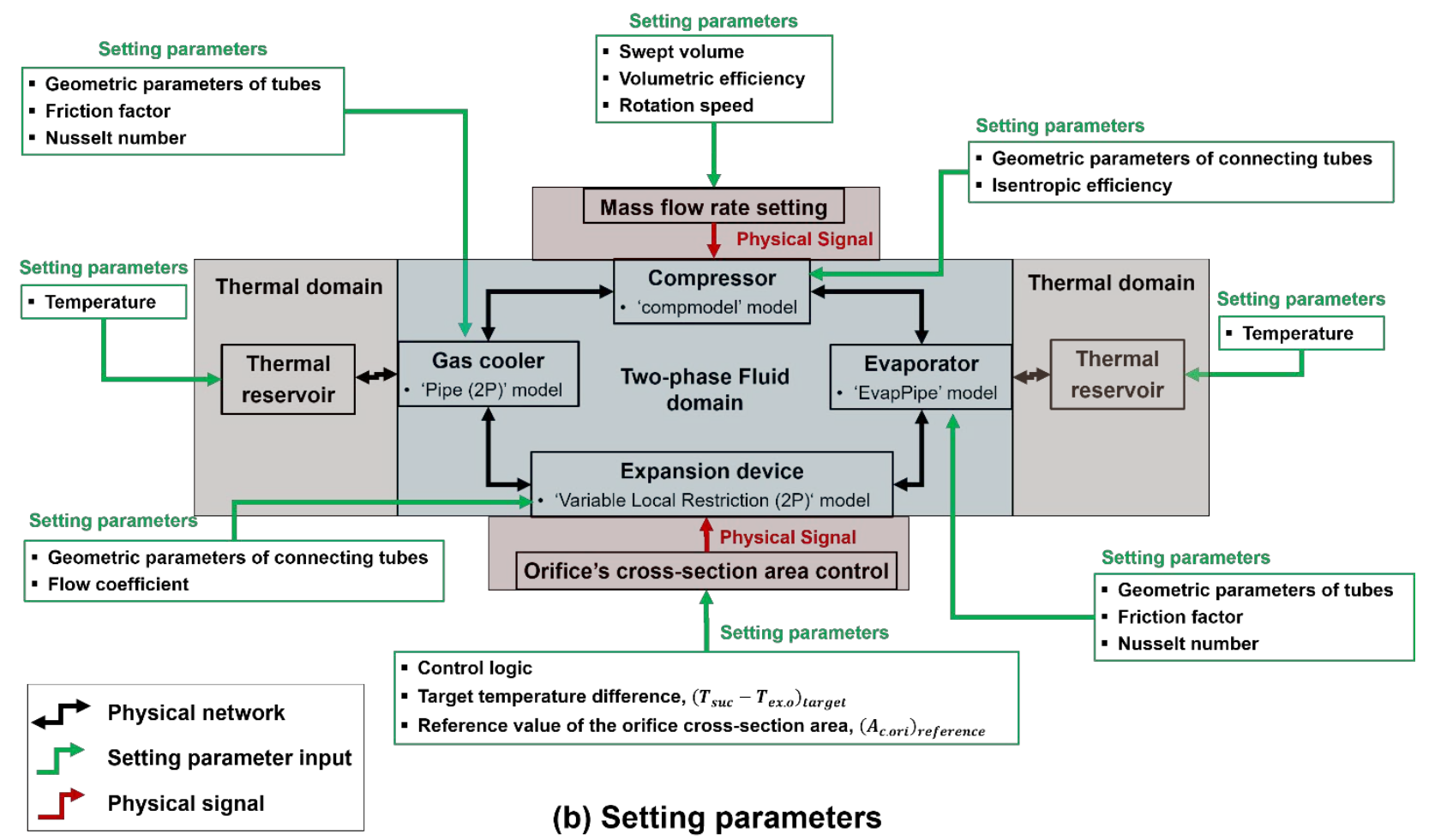

Fig. 3: (a) system model in the Simscape ${ }^{\mathrm{TM}} / \mathrm{MATLAB}$, (b) setting parameters.

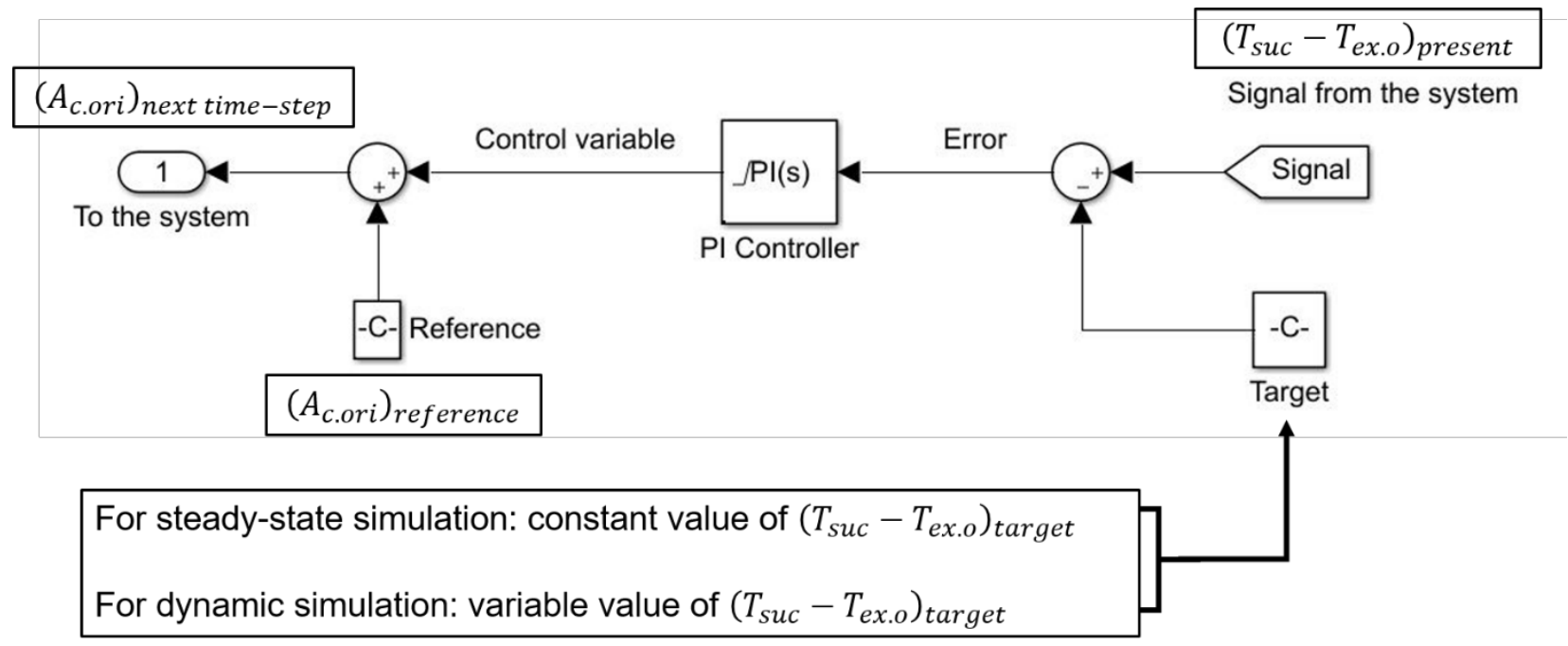

Fig. 4: Control logic for the orifice opening in the Simulink ${ }^{\circledR} /$ MATLAB.

\subsection{System model description}

Fig. 3 (a) shows the heat pump system model. The system consists of four subsystems; a compressor, a gas cooler, an expansion device, and an evaporator. Each subsystem represents each main component of the experimental heat pump. Fig. 3 (b) describes the setting parameters for each subsystem model and indicates the physical network.

In Fig. 3 (a), the compressor model consists of the 'compmodel' block which is the user-defined model. The model's geometric parameters, such as the swept volume and diameters of connecting tubes, were set up with the identical values of the experimental compressor. The black box named 'R-744 mass flow rate setting' indicates the refrigeration mass flow rate calculation. The setting value of the mass flow rate is calculated based on the input rotation speed, the refrigerant density at the suction, the swept volume, and the volumetric efficiency. The calculated mass flow rate then becomes the input of the 'compmodel' block. In the black box, a subsystem named 'vol efficiency' represents volumetric efficiency calculation. The consisting equations for the 'compomodel', 'R-744 mass flow rate setting', and 'vol efficiency' will be mentioned in Section 2.3.

In the gas cooler model, three 'Pipe (2P)' blocks represent three inner-tubes in the experimental gas cooler. 
The hydraulic diameter and the length of the 'Pipe (2P)' blocks are $2.8 \mathrm{~mm}$ and $13.6 \mathrm{~m}$, respectively, which are identical with that of the experimental gas cooler. The evaporator model consists of ten 'EvapPipe' blocks which represent ten channels of the refrigerant flow in the experimental evaporator. In the model, the hydraulic diameter of 'EvapPipe' was assumed $3 \mathrm{~mm}$; thereby the length of 'EvapPipe' was determined to $6.9 \mathrm{~m}$ based on the heat transfer area and the number of refrigerant flow channels in the experimental evaporator. In the gas cooler and evaporator, all the 'Pipe (2P)' and 'EvapPipe' blocks are connected to each temperature setting block that represents thermal reservoirs. When the refrigerant flows into each 'Pipe (2P)' and 'EvapPipe', the flow is uniformly distributed in each 'Pipe (2P)' and 'EvapPipe'.

The expansion device model consists of the 'Variable Local Restriction (2P)' block and the 'Control box Crosssection area' block. The 'Variable Local Restriction (2P)' block represents an orifice. The diameters of tubes in which connecting to the 'Variable Local Restriction (2P)' model were set up with the identical values of the experimental EEV. The cross-section area of the orifice is controlled at the 'Control box Cross-section area' block. Fig. 4 illustrates the control logic of the expansion device. The target temperature difference between the suction and the expansion device outlet, $\left(T_{\text {suc }}-T_{\text {ex.o }}\right)_{\text {target }}$, becomes the control 'Target'. The temperature difference at the present step, $\left(T_{\text {suc }}-T_{\text {ex.o }}\right)_{\text {present }}$, represents the 'Signal' from the system. The 'Control variable' is calculated by PI-method. The proportional and integral coefficients of the PImethod were obtained by the linearization approach using 'PID Tuner' supported by the Simulink. The cross-section area of the orifice for the next time-step, $\left(A_{c . o r i}\right)_{\text {next time-step }}$, was calculated based on the reference value, $\left(A_{c . o r i}\right)_{\text {reference, }}$, considering the obtained 'Control variable'.

The four subsystems are connected with the blue lines representing the 'Two-Phase Fluid (2P)' domain. During the simulations, a set of physical variables of the refrigerant, which are computed in each physical block, transfers to the adjacent physical blocks and affect each other. The orange lines represent the 'Thermal' domain where heat transfer happens. In the 'Thermal' domain, the heat transports from high temperature to low temperature based on physical law. The maroon lines in the compressor model represent the 'Physical Signals' domain. The black lines represent the 'Simulink' domain. Both 'Physical signals' and 'Simulink' domains indicate signal networks. However, signals in the 'Physical signals' domain are with physical units while the signals in the 'Simulink' domain are without physical units, it contains numbers. The blocks, namely 'Point 1 to 4', check the refrigerant states at each position and display their property values.

A table of R-744 properties obtained from Lemmon et al. ${ }^{21)}$ is set up in the MATLAB environment. Properties on this table are parameterized by pressure and normalized the specific internal energy. This table is brought into the Simscape's physical domain using the 'Two-Phase Fluid
Properties (2P)' block. Properties that are not directly specified in the table are going to be determined by curvefitted interpolation during the simulation. A property of the refrigerant in the saturated state, i.e., the mixture of the saturated-liquid and the saturated-vapor $\left(\zeta_{2}\right)$ is determined by weighting the saturated vapor quality, linearly, as follows:

$$
\zeta_{2}=(1-x) \zeta_{L}+x \zeta_{V}
$$

where $x$ represents the vapor quality. The subscripts $L$ and $V$ indicate the saturated liquid state and the saturated vapor state, respectively.

While, in an actual system, a compressor lubricant oil has a significant effect on system performance. In the present modeling, all the effect due to the presence of lubricant oil is not taken into account.

\subsection{Component model description}

In the following subsections, basic mathematical equations in each physical block model are briefly described based on Simscape reference ${ }^{22)}$.

\subsubsection{Compressor}

According to Winkler $(2009)^{23)}$, in the transient simulation of a vapor compression system, the compressor is treated as a quasi steady-state component in most cases that the calculated mass flow rate and discharge temperature instantaneously update based on the current suction conditions and discharge pressure. This assumption is reasonable because the timescales associated with the variation of the compressor mass flow rate are very small compared to timescales associated with heat exchanger performance and refrigerant charge distribution. Also, dynamic modeling of a compressor with considering compressor motor needs an expensive computation cost and it requires very small of time steps to be included in a system-level simulation ${ }^{24)}$. In this circumstance, there are two promising options in the compressor modeling method utilized in a system simulation; one is the map-based modeling and the other is efficiency-based modeling. A map-based model is based on manufacturer data, however, the data were obtained under steady-state conditions. Hence, the map-based model is valid only within a limited range. Besides, it is hard to take into consideration all the transient phenomena that probably influence the compressor performance during transient periods. While efficiency-based modeling has a disadvantage that it requires more effort to develop a model than using the map-based modeling approach. However, after tuning procedure, efficiency-based models can follow up with dynamic behavior as well as match actual systems. Due to this reason, the present compressor modeling adopted the efficiency-based modeling approach.

In Fig. 3 (a), 'compmodel' operates on the following 
assumptions:

1. The compressor is treated as a quasi steady-state component.

2. The pressure drop of the refrigerant flow at the suction and the discharge connecting tube is neglected.

3. Heat gain or loss of the compressor's body is neglected.

4. The compression process of the refrigerant is isentropic.

5. Mechanical efficiency is neglected.

Mass conservation equation is as follows:

$$
\dot{m}_{\text {suc }}=\dot{m}_{\text {dis }}
$$

where, $\dot{m}$ represents the refrigerant mass flow rate. The subscripts suc and dis indicate the suction and the discharge, respective, The refrigerant mass flow rate is calculated by:

$$
\dot{m}_{\text {suc }}=\eta_{v} \rho_{\text {suc }} V_{\text {comp }} S \text {, }
$$

where $\eta_{v}, \rho_{\text {suc }}, V_{\text {comp }}$, and $S$ represent the volumetric efficiency, the refrigerant density at the suction, the compressor swept volume, and the compressor rotation speed, respectively. Here, the Eq. (9) is applied to the ' $\mathrm{R}$ 744 mass flow rate setting' in Fig. 3 (a). Compressor power is calculated by:

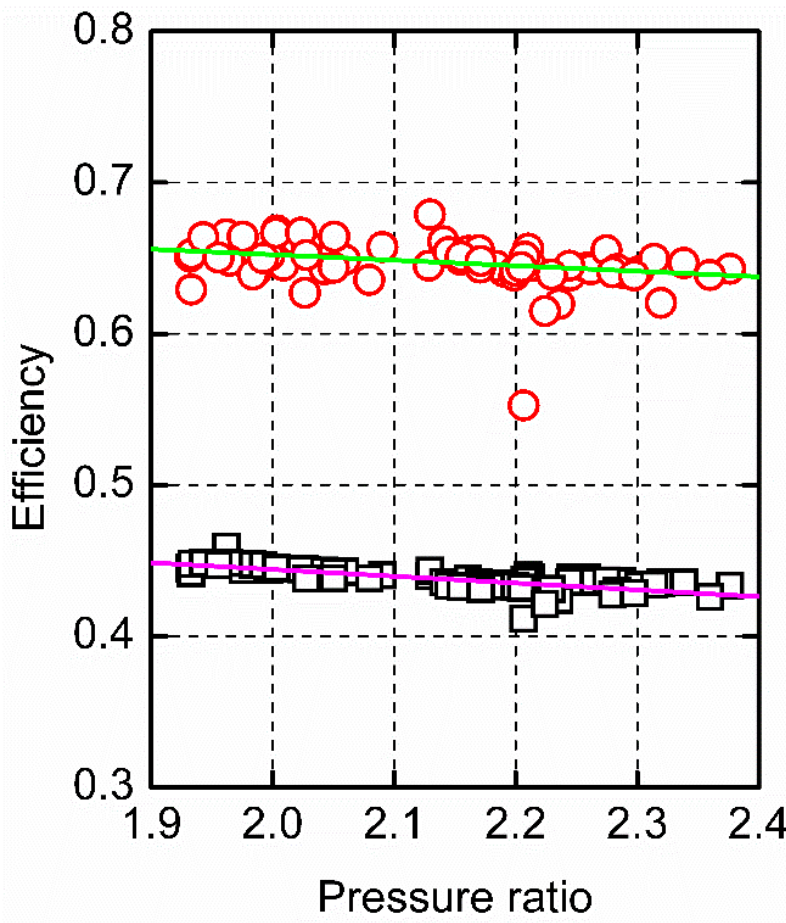

$$
\dot{W}=\left[\dot{m}\left(h+\frac{(G v)^{2}}{2}\right)\right]_{d i s}-\left[\dot{m}\left(h+\frac{(G v)^{2}}{2}\right)\right]_{s u c},
$$

where $h, G, v$, and $\dot{W}$ represent the specific enthalpy of the refrigerant, the refrigerant mass flux, the specific volume of the refrigerant, and the compressor power, respectively. The specific enthalpy of the refrigerant at the discharge is given by:

$$
h_{d i s}=\frac{h_{\text {dis.s }}-h_{s u c}}{\eta_{s}}+h_{s u c}
$$

where $h_{\text {dis.s }}$ and $\eta_{s}$ represent the specific enthalpy of the refrigerant at the discharge by isentropic compression and the isentropic efficiency, respectively.

The volumetric efficiency $\left(\eta_{v}\right)$ and isentropic efficiency $\left(\eta_{s}\right)$ were derived from a set of 63 experimental data obtained under each steady-state condition independently, using the experimental heat pump system mentioned in Section 2.1. The experimental data are depicted in Fig. 5. The pressure ratio in the horizontal axis represents the ratio of the discharge pressure based on the suction pressure. In Fig. 5, the experimental volumetric efficiency and the experimental isentropic efficiency were computed from the following equations:
Experimental results (Number of data: 63 )
$\square$ Volumetric
0 Isentropic

Fitting equations

$$
-\eta_{\mathrm{v}}=0.5341-0.045\left(\mathrm{P}_{\text {dis }} / \mathrm{P}_{\text {suc }}\right)
$$$$
{ }^{*} \mathrm{AD}=0.04 \%,{ }^{* *} \mathrm{MD}=0.81 \%
$$$$
\eta_{\mathrm{s}}=0.7398-0.0438\left(\mathrm{P}_{\mathrm{dis}} / \mathrm{P}_{\text {suc }}\right)
$$$$
{ }^{*} \mathrm{AD}=0.26 \%,{ }^{* *} \mathrm{MD}=1.47 \%
$$

\section{* Average deviation \\ ** Mean deviation}

Fig. 5: Experimental data of the compressor efficiency. 


$$
\begin{aligned}
& \eta_{v . \exp }=\left(\frac{\dot{m}_{r . \exp }}{\rho_{\text {suc }} V_{\text {comp }} S}\right), \\
& \eta_{\text {s.exp }}=\left(\frac{h_{\text {dis.s }}-h_{s u c}}{h_{\text {dis }}-h_{\text {suc }}}\right) .
\end{aligned}
$$

Based on the experimental efficiencies, the fitting equations were derived as follows:

$$
\begin{aligned}
& \eta_{\text {v.pred }}=0.5341-0.045\left(\frac{P_{d i s}}{P_{\text {suc }}}\right), \\
& \eta_{\text {s.pred }}=0.7398-0.0438\left(\frac{P_{d i s}}{P_{\text {suc }}}\right) .
\end{aligned}
$$

The obtained fitting equations are applied to the compressor model. The Eq. (14) is applied to the 'vol efficiency' in Fig. 3 (a). The Eq. (15) is stated in the source code of 'compmodel'.

\subsubsection{Gas cooler and evaporator}

The gas cooler and evaporator models were constructed based on the following assumptions:

1. Refrigerant flow is one dimensional and fully developed.

2. The pressure drop of the refrigerant flow at the inlet and the outlet of each tube is neglected.

3. The gravitational effect of the refrigerant flow is neglected.

4. The liquid-vapor mixture flow is treated as a homogeneous flow.

5. The effect of HX's mass and its thermal conduction are neglected.

6. The second-side working fluid of each $\mathrm{HX}$ is considered a stagnant thermal reservoir.

7. The heat transfer rate is calculated concerning the refrigerant bulk temperature at the center of each tube (Fig. 6).

Based on the above assumptions, the 'Pipe (2P)' model and 'EvapPipe' model calculate the refrigerant heat transfer rate and pressure drop base on conservation equations. Fig. 6 shows the segment for mass, energy and pressure drop calculation.

Mass and energy conservation equations are calculated based on the segment described in Fig. 6 (a). A single tube is treated as a unit segment. Mass conservation is as follows:

$$
\left[\left(\frac{\partial \rho_{c e n}}{\partial P_{c e n}}\right)_{u_{c e n}}\left(\frac{d P_{c e n}}{d t}\right)+\left(\frac{\partial \rho_{c e n}}{\partial u_{c e n}}\right)_{P_{c e n}}\left(\frac{d u_{c e n}}{d t}\right)\right] V=
$$

$\dot{m}_{o}+\dot{m}_{i}$

where $\rho, P, u, t$, and $V$ represent the refrigerant density, the refrigerant pressure, the specific internal energy of the refrigerant, the time and the inner volume of the tube, respectively. The subscripts $i, o$, and cen indicate the inlet of the tube, the outlet of the tube, and the center of the refrigerant volume inside the tube. Energy conservation equation is given as follows:

$$
\begin{gathered}
{\left[\left(\dot{m}_{i}+\dot{m}_{o}\right)\left(\frac{d u_{c e n}}{d t}\right)+u_{c e n}\left(\frac{d \dot{m}_{i}}{d t}+\frac{d \dot{m}_{o}}{d t}\right)\right]=} \\
{\left[\dot{m}\left(h+\frac{(G v)^{2}}{2}\right)\right]_{o}+\left[\dot{m}\left(h+\frac{(G v)^{2}}{2}\right)\right]_{i}+\dot{Q},}
\end{gathered}
$$

where $\dot{Q}$ represents the heat transfer rate of the refrigerant flow. Here, based on the mentioned assumptions 5,6 , and 7 , the heat transfer rate can be calculated as follows:

$$
\dot{Q} \cong \lambda_{r} A\left(T_{\text {r.cen }}-T_{\text {res }}\right),
$$

where $\lambda_{r}, A, T_{\text {ref.cen }}$, and $T_{\text {res }}$ represent the heat transfer coefficient of the refrigerant flow, the total heat transfer area of the tube, the refrigerant temperature at the center of the tube, and the thermal reservoir's temperature, respectively. The heat transfer coefficient for the singlephase refrigerant flow is given by:

$$
\lambda_{r .1}=\left(\frac{k_{1 . c e n} N u_{1}}{D_{h}}\right)
$$

where $k_{1 . c e n}$ and $N u_{1}$ represent the thermal conductivity of the refrigerant and the Nusselt number of the single-phase refrigerant flow, respectively. The heat transfer coefficient for the two-phase refrigerant flow can be calculated as:

$$
\lambda_{r .2}=\left(\frac{k_{c e n . L} N u_{2}}{D_{h}}\right)
$$

where $k_{c e n . L}$ and $N u_{2}$ represent the thermal conductivity of the saturated liquid state of the refrigerant and the Nusselt number of the two-phase refrigerant flow, respectively. 


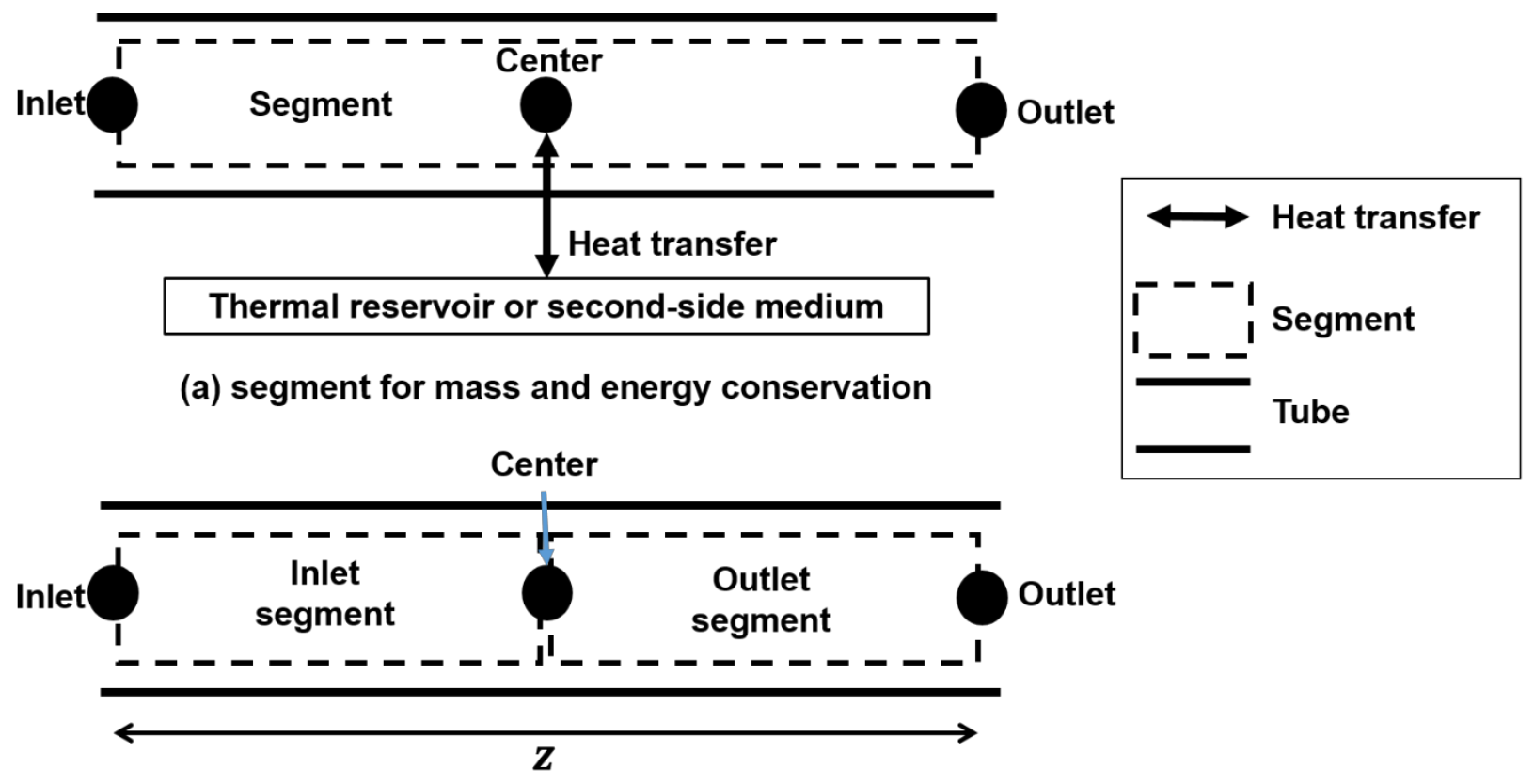

(b) segment for pressure drop

Fig. 6: Segment for calculation.

The pressure drop equation of refrigerant flow inside a tube can be written as follows:

$$
\begin{aligned}
& \left(-\frac{d P}{d z}\right)_{\text {total }}=\left(-\frac{d P}{d z}\right)_{\text {friction }}+ \\
& \left(-\frac{d P}{d z}\right)_{\text {acceleration }}+\left(-\frac{d P}{d z}\right)_{\text {gravitation }}+ \\
& \left(-\frac{d P}{d z}\right)_{\text {minor }}
\end{aligned}
$$

In the right hand of the Eq. (21), the last term represents the pressure drop due to the change of the cross-section area of the refrigerant flow at the inlet and the outlet. Based on the above assumptions 2 and 3, the Eq. (21) is given by the following simplified form:

$$
\left(-\frac{d P}{d z}\right)_{\text {total }}=\left(-\frac{d P}{d z}\right)_{\text {friction }}+\left(-\frac{d P}{d z}\right)_{\text {acceleration }}
$$

Fig. 6 (b) shows the segments for pressure drop calculation. A single tube consists of two segments; the inlet segment and the outlet segment. The Eq. (22) is applied to each segment with the following form of pressure drop equations, respectively:

Inlet segment:

$$
P_{i}-P_{c e n}=\left(\frac{f G_{i}^{2} v_{c e n}}{2 D_{h}}\right)\left(\frac{z}{2}\right)+G_{i}\left|G_{i}\left(v_{c e n}-v_{i}\right)\right|
$$

Outlet segment:

$$
P_{o}-P_{c e n}=\left(\frac{f G_{o}^{2} v_{c e n}}{2 D_{h}}\right)\left(\frac{z}{2}\right)+G_{o}\left|G_{i}\left(v_{c e n}-v_{o}\right)\right|,
$$

where $z, f$, and $D_{h}$ represent the length of the tube, the Darcy friction factor, and the hydraulic diameter of the tube, respectively. Except for the Darcy friction factor and the Nusselt number, the mentioned equations (Eq. 16 - 24) consist of geometric parameters and thermodynamic properties of the refrigerant. The model and correlations of the Darcy friction factor and the Nusselt number which applied to the 'Pipe (2P)' and 'EvapPipe' are tabulated in Table 5. 
Table 5. Model and correlations for friction factor and Nusselt number.

\begin{tabular}{|c|c|c|}
\hline \multicolumn{3}{|c|}{ Friction factor } \\
\hline $\begin{array}{l}\text { Single-phase } \\
\text { laminar flow }\end{array}$ & $f=\left(\frac{64}{R e_{1}}\right)$. & \\
\hline $\begin{array}{l}\text { Single-phase } \\
\text { turbulent flow }\end{array}$ & $\begin{array}{l}\text { Haaland }^{25)} \\
f=\left\{-1.8 \log _{10}\left[\frac{6.9}{R e_{1}}+\left(\frac{\varepsilon / D_{h}}{3.7}\right)^{1.11}\right]\right\}^{-2} .\end{array}$ & \\
\hline $\begin{array}{l}\text { Two-phase } \\
\text { flow boiling }\end{array}$ & Haaland ${ }^{25)}$, using two-phase Reynolds number $\left(R e_{2}=\frac{G_{2} D_{h}}{\mu_{2}}\right)$. & \\
\hline \multicolumn{3}{|c|}{ Nusselt number } \\
\hline $\begin{array}{l}\text { Single-phase } \\
\text { laminar flow }\end{array}$ & $N u_{1}=3.66 . .^{28)}$ & \\
\hline $\begin{array}{l}\text { Single-phase } \\
\text { turbulent flow }\end{array}$ & $\begin{array}{l}\text { Gnielinski }^{26)} \\
N u_{1}=\frac{\left(\frac{f}{8}\right)\left(R e_{1}-1000\right) P r_{1}}{1+12.7\left(\frac{f}{8}\right)^{0.5}\left(P r_{1}^{\frac{2}{3}}-1\right)} . \\
\text { Here, the friction factor is calculated by Haaland }{ }^{25)} \text {. }\end{array}$ & \\
\hline $\begin{array}{l}\text { Two-phase } \\
\text { flow boiling }\end{array}$ & 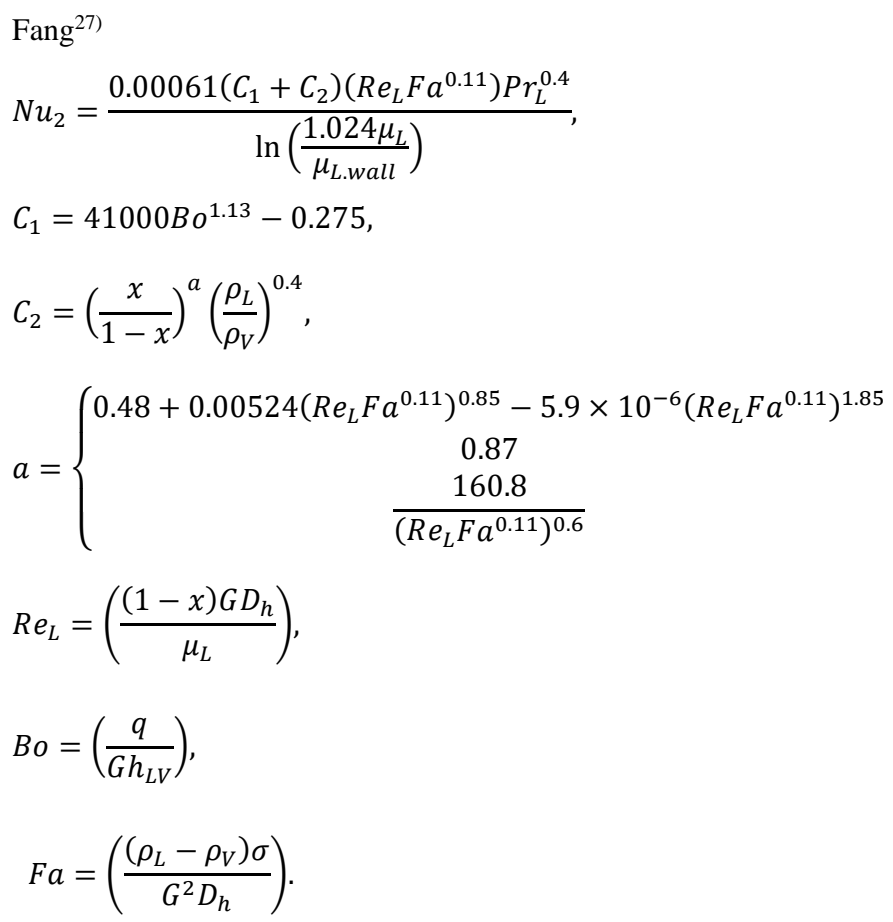 & $\begin{array}{c} \\
\text { if, } 600 \leq\left(R e_{L} F a^{0.11}\right) \leq 6000 \\
\text { if, } 6000<\left(R e_{L} F a^{0.11}\right) \\
\end{array}$ \\
\hline
\end{tabular}


In the present model, the Nusselt number of R-744 transcritical flow at the gas cooler is calculated by Gnielinski $^{26}$ correlation. Yin et al. ${ }^{29)}$ adopted the Gnielinski ${ }^{26)}$ correlation for modeling R-744 transcritical flow in $0.79 \mathrm{~mm}$ of the refrigerant channel and reported that the calculated heat rejection rate is well-matched with their experimental heat rejection rate of the gas cooler, with an error of $\pm 2 \%$. Rieberer ${ }^{30}$ compared six correlations for R-744 flow in $7.8 \mathrm{~mm}$ of smooth tubes. Among them, Gnielinski ${ }^{26)}$ correlation showed the best prediction result that compared to the measured heat transfer coefficient within $\pm 30 \%$ over a wide temperature range. Besides, according to Petterson et al. $^{31}$, Gnielinski ${ }^{26)}$ correlation predicts well for cases of microscaled channels, also. In the present study, the hydraulic diameter of the refrigerant flow in the gas cooler is 2.8 $\mathrm{mm}$; this value lies within the valid range mentioned in the previous literature ${ }^{29), 30)}(0.79 \mathrm{~mm}$ to $7.8 \mathrm{~mm})$.

Fang $^{27)}$ analyzed 2956 experimental data of R-744 flow boiling over a wide range of operating conditions $\left(-40^{\circ} \mathrm{C}\right.$ to $27{ }^{\circ} \mathrm{C}$ of evaporation temperature; $97 \mathrm{~kg} \mathrm{~m}^{-2} \mathrm{~s}^{-1}$ to 1400 $\mathrm{kg} \mathrm{m}^{-2} \mathrm{~s}^{-1}$ of mass flux; $3.9 \mathrm{~kW} \mathrm{~m}^{-2}$ to $40 \mathrm{~kW} \mathrm{~m}^{-2}$ of heat flux) and hydraulic diameter of the flow channel $(0.53 \mathrm{~mm}$ to $7.75 \mathrm{~mm}$ ). Based on the database, Fang ${ }^{27)}$ proposed a correlation of the Nusselt number for R-744 flow boiling by adding a non-dimensional number which takes into account the effect of bubble formation and departure. The proposed correlation predicts the boiling heat transfer coefficient of R-744 within $\pm 30 \%$ error against $90 \%$ of the database. The operating conditions and the hydraulic diameter of the evaporator in the present manuscript lie in the applicable range of the Fang correlation. Thus, the Fang correlation is used for the Nusselt number calculation of R-744 flow boiling in the evaporator.

\subsubsection{Orifice}

An orifice as an expansion device was constructed employing the 'Variable Local Restriction (2P)' model in Fig. 3 (a). The model operates under the following assumptions:

1. The orifice is a rigid body.

2. Heat gain or loss of the orifice body is neglected.

3. The expansion process of the refrigerant flow is isenthalpic.

4. The refrigerant flow is one dimensional.

Mass and energy conservation equations are as follows:

$$
\begin{aligned}
& \dot{m}_{e x . i}=\dot{m}_{e x . o}, \\
& h_{e x . i}=h_{e x . o} .
\end{aligned}
$$

Here, the subscript, ex, represents the expansion device. The refrigerant mass flow rate due to the irreversible pressure drop is calculated as follows:

$$
\dot{m}_{r}=C_{D} A_{c . o r i}\left[\frac{2\left(P_{i}-P_{o}\right)}{v_{\text {ori }} K}\right]^{0.5},
$$

where $C_{D}, A_{c . \text { ori }}, v_{\text {ori }}$, and $K$ represent the flow coefficient, the cross-section area of the orifice, the specific volume of the refrigerant (defined at the orifice), and the correction factor, respectively. The correction factor $(K)$ is applied by the Simscape's default setting to avoid encountering numerical errors and implement a smooth computing procedure during simulations. The flow coefficient $\left(C_{D}\right)$ of a certain valve is specified based on its geometric shape and size; in the present model, the flow coefficient was set the fixed default value, 0.64 .

\subsection{Simulation procedure}

Fig. 7 describes a simulation flow chart. When a transient simulation starts, Simscape solver builds up a physical network of the heat pump system model based on the setting parameters in each component model and the input values (Phase A). Then, a system of equations is constructed based on the constructed physical network (Phase B). The solver analyzes the constructed system of equations and eliminates variables that are not needed to solve the system of equations. Then, the solver computes the initial conditions by finding initial values (at $t=0$ ) for all variables in each component model (Phase C). These initial values must be exactly satisfied with the whole physical conservation equations. When the solver finds the initial values, it starts computing by the end of the set simulation time (Phase D). After each simulation finished, the result values such as the refrigerant mass flow rate, thermodynamic states at each point, capacities of each HX, and compressor's power, were obtained in each time-step (Phase E).

In this study, one of the variable time-step implicit solvers, 'ode23t', was selected as the solver of simulation the heat pump system. It is because the 'ode23t' showed the shortest running time compared to among other variable time-step implicit solvers.

For the steady-state simulations, a long enough time, 3600 seconds, was set for the transient simulation time. After each transient simulation finished, the operating parameters of the heat pump system model, such as the refrigerant mass flow rate, pressure, and temperature were checked. When these values lie within the experimental uncertainties without any variation, it was decided that the heat pump system model reached a steady-state. 


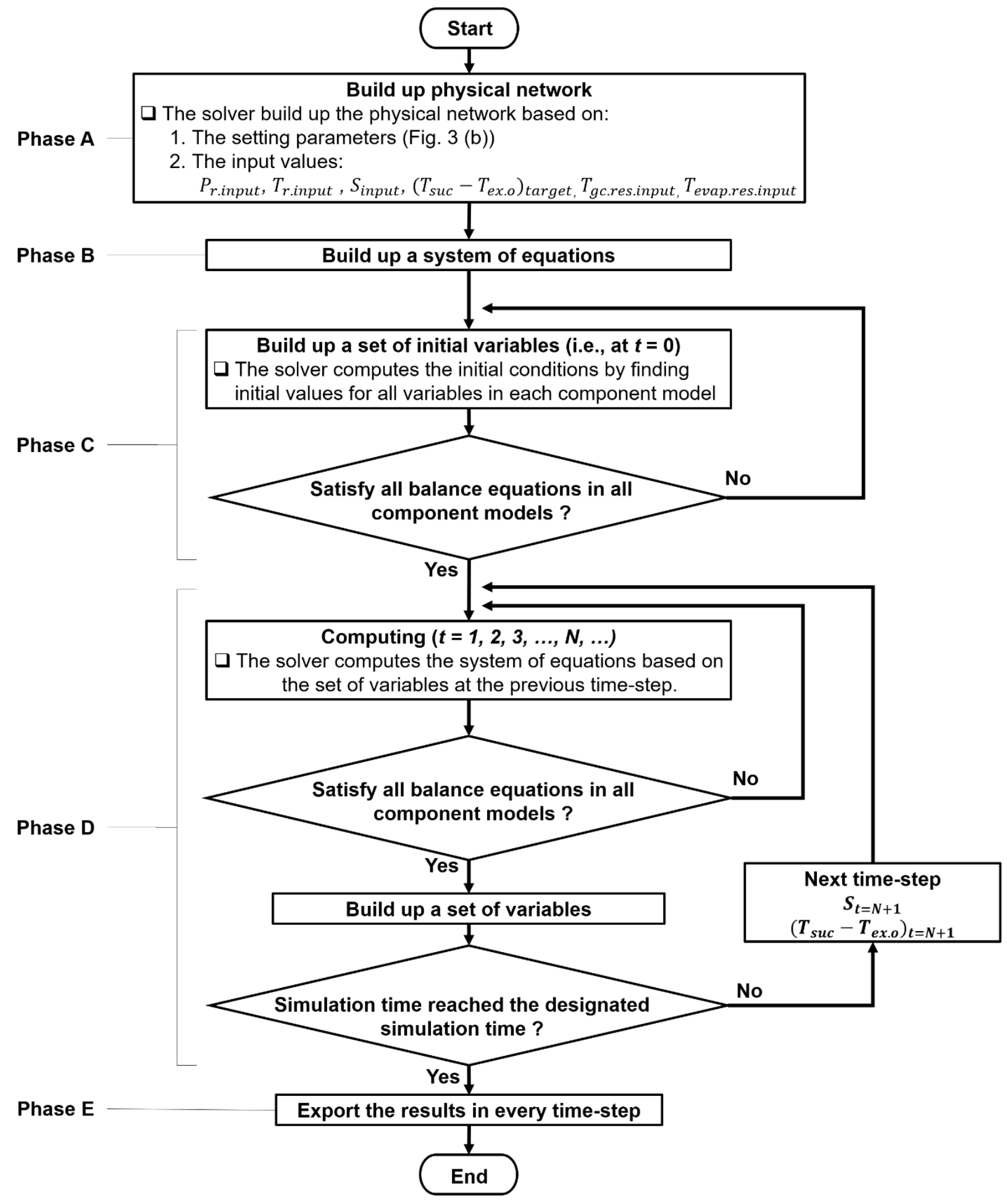

Fig. 7: Flow chart. 


\section{Results and discussion}

\subsection{Steady-state performance}

A set of experimental conditions in steady-states is summarized in Table 6. Each experiment was carried out to achieve the target cooling and heating capacities, primarily. The adjusting parameters for the cooling capacity were 1.6 and $1.8 \mathrm{~kW}$ for the evaporator. The heating capacity of the gas cooler changes from 2.4 to 3 $\mathrm{kW}$ with a step of $0.2 \mathrm{~kW}$. The experimental results corresponding to each case are tabulated in Table 7.

Table 8 shows simulation conditions corresponding to each experimental case. The rotation speed of the compressor model was selected as the identical value with the rotation speed obtained from each experiment. The target temperature difference between the suction and the expansion device outlet, $\left(T_{\text {suc }}-T_{\text {ex.o }}\right)_{\text {target }}$, was adjusted to fulfill the experimental mass flow rate of the refrigerant. The simulation results are tabulated in Table 9.

Fig. 8 presents the prediction error of the calculated refrigerant mass flow rate, capacities of each $\mathrm{HX}$, and
COPs. The simulation results show a good agreement for the refrigerant mass flow rate, heating, and cooling capacity of each HX, compressor power, and COPs. As shown in Fig. 8 (a), the model predicts the measured refrigerant mass flow rate in a maximum error of $\pm 6 \%$. Also, the model predicts both the cooling capacity of the evaporator and the heating capacity of the gas cooler within an error of $\pm 5 \%$. In Fig. 8 (b), the simulation model under-predicts the compressor power. The compressor model predicts similar discharge pressures with less input power as compared to the corresponding actual compressor. As the suction pressure in an actual case has the same value as that of its ideal case; the system needs higher compressor power to lift the refrigerant pressure to the same level as in the ideal case. It is because of the irreversible losses during the actual compression process. In the present system model, the compressor is simply modeled with several assumptions, thus, it is hard to consider all the sources of losses in an actual compression process. Consequently, as shown in Fig. 8 (c), the simulation model over-predicts the COP values of the experimental system within an error of $7 \%$.

Table 6. Experimental conditions in steady-state.

\begin{tabular}{|c|c|c|c|c|c|c|c|c|c|c|c|}
\hline \multirow{4}{*}{ Case } & \multirow{3}{*}{ Target } & \multicolumn{4}{|c|}{ Gas cooler } & \multicolumn{4}{|c|}{ Evaporator } & \multirow{3}{*}{$\begin{array}{c}\text { Comp. } \\
S \\
\end{array}$} & \multirow{3}{*}{$\begin{array}{c}\text { EEV } \\
\text { Opening step } \\
\end{array}$} \\
\hline & & \multicolumn{2}{|c|}{ Water } & \multicolumn{2}{|c|}{ Refrigerant } & \multicolumn{2}{|c|}{ Water } & \multicolumn{2}{|c|}{ Refrigerant } & & \\
\hline & & $T_{\text {w.i.gc }}$ & $\dot{V}_{w . g c}$ & $P_{\text {r.i.gc }}$ & $T_{\text {r.i.gc }}$ & $T_{\text {w.i.evap }}$ & $\dot{V}_{\text {w.evap }}$ & $P_{\text {r.i.evap }}$ & $h_{\text {r.i.evap }}$ & & \\
\hline & $\mathrm{kW}$ & ${ }^{\circ} \mathrm{C}$ & $\mathrm{L} / \mathrm{h}$ & $\mathrm{MPa}$ & ${ }^{\circ} \mathrm{C}$ & ${ }^{\circ} \mathrm{C}$ & $\mathrm{L} / \mathrm{h}$ & $\mathrm{MPa}$ & $\mathrm{kJ} / \mathrm{kg}$ & $\mathrm{rev} / \mathrm{s}$ & - \\
\hline 1 & $\dot{Q}_{\text {evap }}=1.6$ & 29.9 & 126.6 & 8.29 & 75.0 & 20.4 & 90.8 & 3.92 & 295.8 & 72 & 225 \\
\hline 2 & $\dot{Q}_{\text {evap }}=1.8$ & 30.0 & 137.3 & 8.32 & 76.6 & 20.4 & 100.0 & 3.94 & 294.4 & 78 & 237 \\
\hline 3 & $\dot{Q}_{\text {evap }}=1.6$ & 29.8 & 118.4 & 8.36 & 68.4 & 20.4 & 134.9 & 4.45 & 295.0 & 60 & 219 \\
\hline 4 & $\dot{Q}_{\text {evap }}=1.8$ & 29.8 & 128.5 & 8.43 & 70.0 & 20.4 & 147.3 & 4.44 & 286.7 & 62 & 179 \\
\hline 5 & $\dot{Q}_{\text {evap }}=1.8$ & 29.8 & 137.2 & 10.0 & 86.0 & 20.4 & 152.9 & 4.45 & 270.9 & 60 & 127 \\
\hline 6 & $\dot{Q}_{g c}=2.4$ & 20.1 & 83.8 & 7.83 & 65.4 & 15.6 & 253.6 & 4.32 & 283.8 & 68 & 245 \\
\hline 7 & $\dot{Q}_{g c}=2.6$ & 20.1 & 91.1 & 7.85 & 66.3 & 15.6 & 273.7 & 4.32 & 283.1 & 74 & 263 \\
\hline 8 & $\dot{Q}_{g c}=2.6$ & 20.1 & 89.3 & 7.92 & 66.4 & 15.6 & 270.9 & 4.32 & 272.2 & 68 & 176 \\
\hline 9 & $\dot{Q}_{g c}=2.8$ & 20.1 & 97.2 & 7.95 & 66.8 & 15.7 & 289.4 & 4.31 & 271.9 & 74 & 192 \\
\hline 10 & $\dot{Q}_{g c}=3.0$ & 20.1 & 103.7 & 8.29 & 69.1 & 15.6 & 318.7 & 4.30 & 247.9 & 70 & 142 \\
\hline 11 & $\dot{Q}_{g c}=3.0$ & 24.9 & 67.6 & 10.0 & 80.5 & 20.5 & 310.7 & 4.85 & 269.2 & 68 & 159 \\
\hline 12 & $\dot{Q}_{g c}=2.8$ & 24.9 & 64.2 & 10.1 & 80.3 & 20.5 & 296.8 & 4.87 & 266.6 & 64 & 146 \\
\hline 13 & $\dot{Q}_{g c}=3.0$ & 24.9 & 69.0 & 10.1 & 82.2 & 20.5 & 318.0 & 4.85 & 263.9 & 68 & 150 \\
\hline 14 & $\dot{Q}_{g c}=2.8$ & 24.9 & 65.1 & 10.4 & 83.8 & 20.5 & 302.7 & 4.85 & 256.9 & 62 & 126 \\
\hline 15 & $\dot{Q}_{g c}=3.0$ & 24.9 & 67.8 & 10.5 & 85.0 & 20.5 & 315.7 & 4.85 & 256.3 & 64 & 129 \\
\hline
\end{tabular}


Table 7. Experimental results in steady-state.

\begin{tabular}{|c|c|c|c|c|c|c|c|c|c|c|c|c|c|c|}
\hline \multirow{4}{*}{ \# } & \multicolumn{4}{|c|}{ Gas cooler } & \multicolumn{5}{|c|}{ Evaporator } & \multirow{3}{*}{$\Delta T_{\text {sup }}$} & \multirow{3}{*}{$\dot{m}_{r}$} & \multirow{3}{*}{$\dot{W}$} & \multirow{3}{*}{$C O P_{c}$} & \multirow{3}{*}{$C O P_{h}$} \\
\hline & \multicolumn{2}{|c|}{ Water } & \multicolumn{2}{|c|}{ Refrigerant } & \multicolumn{2}{|c|}{ Water } & \multicolumn{3}{|c|}{ Refrigerant } & & & & & \\
\hline & $T_{\text {w.o.gc }}$ & $\dot{Q}_{w . g c}$ & $T_{\text {r.o.gc }}$ & $\dot{Q}_{r . g c}$ & $T_{\text {w.o.evap }}$ & $\dot{Q}_{\text {w.evap }}$ & $T_{\text {r.o.evap }}$ & $P_{\text {r.o.evap }}$ & $\dot{Q}_{\text {r.evap }}$ & & & & & \\
\hline & ${ }^{\circ} \mathrm{C}$ & kW & ${ }^{\circ} \mathrm{C}$ & $\mathrm{kW}$ & ${ }^{\circ} \mathrm{C}$ & $\mathrm{kW}$ & ${ }^{\circ} \mathrm{C}$ & $\mathrm{MPa}$ & $\mathrm{kW}$ & ${ }^{\circ} \mathrm{C}$ & $\mathrm{kg} / \mathrm{h}$ & $\mathrm{kW}$ & - & - \\
\hline 1 & 45.0 & 2.21 & 32.5 & 2.31 & 4.9 & 1.63 & 5.4 & 3.77 & 1.73 & 2.5 & 45.4 & 0.63 & 2.59 & 3.51 \\
\hline 2 & 45.1 & 2.41 & 32.3 & 2.52 & 5.0 & 1.78 & 5.7 & 3.76 & 1.88 & 2.9 & 48.5 & 0.69 & 2.58 & 3.49 \\
\hline 3 & 45.0 & 2.07 & 32.5 & 2.16 & 9.9 & 1.63 & 11.9 & 4.32 & 1.72 & 3.5 & 45.2 & 0.49 & 3.33 & 4.22 \\
\hline 4 & 45.0 & 2.26 & 31.3 & 2.35 & 9.9 & 1.79 & 12.1 & 4.44 & 1.88 & 3.8 & 46.3 & 0.52 & 3.44 & 4.35 \\
\hline 5 & 45.1 & 2.42 & 29.5 & 2.54 & 10.0 & 1.85 & 11.9 & 4.33 & 1.95 & 3.5 & 43.6 & 0.65 & 2.85 & 3.72 \\
\hline 6 & 45.0 & 2.42 & 29.3 & 2.52 & 9.0 & 1.94 & 10.7 & 4.16 & 2.04 & 3.8 & 48.9 & 0.52 & 3.73 & 4.65 \\
\hline 7 & 45.0 & 2.63 & 29.2 & 2.73 & 9.0 & 2.10 & 10.3 & 4.14 & 2.20 & 3.6 & 52.5 & 0.57 & 3.68 & 4.61 \\
\hline 8 & 45.0 & 2.58 & 27.0 & 2.68 & 9.0 & 2.08 & 10.6 & 4.16 & 2.19 & 3.8 & 48.7 & 0.52 & 4.00 & 4.96 \\
\hline 9 & 45.0 & 2.90 & 27.0 & 2.90 & 9.1 & 2.24 & 8.7 & 4.12 & 2.35 & 3.1 & 52.6 & 0.58 & 3.86 & 5.00 \\
\hline 10 & 45.0 & 3.00 & 20.4 & 3.12 & 9.0 & 2.44 & 9.1 & 4.14 & 2.56 & 2.4 & 50.2 & 0.58 & 4.21 & 5.17 \\
\hline 11 & 63.0 & 2.99 & 29.2 & 3.11 & 13.9 & 2.36 & 14.6 & 4.68 & 2.46 & 2.8 & 55.4 & 0.71 & 3.32 & 4.21 \\
\hline 12 & 63.0 & 2.83 & 28.5 & 2.96 & 13.9 & 2.25 & 14.3 & 4.68 & 2.35 & 2.6 & 52.4 & 0.67 & 3.36 & 4.22 \\
\hline 13 & 62.9 & 3.04 & 27.6 & 3.16 & 14.0 & 2.41 & 14.7 & 4.64 & 2.51 & 3.2 & 54.4 & 0.72 & 3.35 & 4.22 \\
\hline 14 & 63.1 & 2.88 & 25.6 & 3.01 & 13.9 & 2.30 & 14.5 & 4.68 & 2.40 & 2.7 & 50.3 & 0.69 & 3.33 & 4.17 \\
\hline 15 & 62.9 & 2.99 & 25.5 & 3.13 & 14.0 & 2.38 & 14.6 & 4.68 & 2.48 & 2.0 & 51.8 & 0.72 & 3.31 & 4.15 \\
\hline
\end{tabular}

Table 8. Simulation conditions in steady-state.

\begin{tabular}{|c|c|c|c|c|c|c|c|c|}
\hline \multirow{4}{*}{ Case } & \multicolumn{8}{|c|}{ Input value } \\
\hline & \multicolumn{3}{|c|}{ Gas cooler } & \multicolumn{3}{|c|}{ Evaporator } & \multirow{2}{*}{$\begin{array}{c}\text { Expansion device } \\
\left(T_{\text {suc }}-T_{\text {ex.o }}\right)_{\text {target }}\end{array}$} & \multirow{2}{*}{$\begin{array}{l}\text { Comp. } \\
S_{\text {input }}\end{array}$} \\
\hline & $T_{\text {gc.res.input }}$ & $P_{\text {r.gc.input }}$ & $T_{r . g c . i n p u t}$ & $T_{\text {evap.res.input }}$ & $P_{\text {r.evap.input }}$ & $T_{\text {r.evap.input }}$ & & \\
\hline & ${ }^{\circ} \mathrm{C}$ & $\mathrm{MPa}$ & ${ }^{\circ} \mathrm{C}$ & ${ }^{\circ} \mathrm{C}$ & $\mathrm{MPa}$ & ${ }^{\circ} \mathrm{C}$ & ${ }^{\circ} \mathrm{C}$ & $\mathrm{rev} / \mathrm{s}$ \\
\hline 1 & 32.0 & 8.3 & 32.0 & 4.5 & 4.5 & 11.0 & 4.0 & 72 \\
\hline 2 & 32.0 & 11.0 & 32.0 & 4.5 & 4.5 & 11.0 & 4.0 & 78 \\
\hline 3 & 31.0 & 7.8 & 32.0 & 9.5 & 4.5 & 11.0 & 2.0 & 60 \\
\hline 4 & 31.1 & 7.9 & 32.0 & 9.5 & 4.5 & 11.0 & 3.5 & 62 \\
\hline 5 & 29.2 & 8.3 & 32.0 & 9.5 & 4.5 & 11.0 & 4.0 & 60 \\
\hline 6 & 29.0 & 8.3 & 32.0 & 8.3 & 4.5 & 11.0 & 2.5 & 68 \\
\hline 7 & 28.5 & 8.2 & 32.0 & 8.3 & 4.5 & 11.0 & 4.0 & 74 \\
\hline 8 & 26.0 & 8.9 & 32.0 & 8.3 & 4.5 & 11.0 & 4.0 & 68 \\
\hline 9 & 26.0 & 8.9 & 32.0 & 8.3 & 4.5 & 11.0 & 3.5 & 74 \\
\hline 10 & 20.0 & 9.0 & 26.0 & 8.0 & 4.5 & 11.0 & 3.5 & 70 \\
\hline 11 & 28.0 & 10.0 & 30.0 & 13.0 & 4.8 & 13.0 & 3.5 & 68 \\
\hline 12 & 27.0 & 10.5 & 30.0 & 13.0 & 4.8 & 13.0 & 4.0 & 64 \\
\hline 13 & 27.0 & 10.4 & 30.0 & 13.0 & 4.8 & 13.0 & 3.5 & 68 \\
\hline 14 & 24.0 & 12.3 & 30.0 & 12.5 & 4.8 & 13.0 & 4.0 & 62 \\
\hline 15 & 24.0 & 12.3 & 30.0 & 12.5 & 4.8 & 13.0 & 4.0 & 64 \\
\hline
\end{tabular}


Table 9. Simulation results in steady-state.

\begin{tabular}{|c|c|c|c|c|c|c|c|}
\hline \multirow{3}{*}{ Case } & \multicolumn{7}{|c|}{ Result } \\
\hline & $\dot{m}_{r}$ & $\Delta T_{\text {sup }}$ & $\dot{Q}_{\text {evap }}$ & $\dot{Q}_{g c}$ & $\dot{W}$ & $C O P_{c}$ & $C O P_{h}$ \\
\hline & $\mathrm{kg} / \mathrm{h}$ & ${ }^{\circ} \mathrm{C}$ & $\mathrm{kW}$ & kW & $\mathrm{kW}$ & - & - \\
\hline 1 & 45.8 & 4.9 & 1.62 & 2.22 & 0.59 & 2.75 & 3.76 \\
\hline 2 & 49.1 & 4.9 & 1.80 & 2.46 & 0.66 & 2.73 & 3.73 \\
\hline 3 & 47.7 & 2.9 & 1.66 & 2.16 & 0.50 & 3.32 & 4.32 \\
\hline 4 & 47.0 & 4.9 & 1.71 & 2.20 & 0.49 & 3.49 & 4.49 \\
\hline 5 & 44.0 & 4.0 & 1.76 & 2.38 & 0.61 & 2.89 & 3.90 \\
\hline 6 & 50.6 & 3.5 & 1.92 & 2.42 & 0.50 & 3.84 & 4.84 \\
\hline 7 & 52.3 & 5.7 & 2.06 & 2.62 & 0.56 & 3.68 & 4.68 \\
\hline 8 & 48.3 & 4.8 & 2.03 & 2.53 & 0.50 & 4.06 & 5.06 \\
\hline 9 & 52.8 & 4.4 & 2.22 & 2.77 & 0.55 & 4.04 & 5.04 \\
\hline 10 & 49.4 & 3.5 & 2.35 & 2.90 & 0.56 & 4.20 & 5.18 \\
\hline 11 & 55.6 & 3.6 & 2.30 & 2.99 & 0.69 & 3.33 & 4.33 \\
\hline 12 & 51.8 & 4.0 & 2.19 & 2.84 & 0.65 & 3.37 & 4.37 \\
\hline 13 & 55.5 & 3.5 & 2.34 & 3.03 & 0.69 & 3.39 & 4.39 \\
\hline 14 & 49.4 & 4.0 & 2.19 & 2.85 & 0.65 & 3.37 & 4.38 \\
\hline 15 & 50.7 & 4.1 & 2.26 & 2.94 & 0.68 & 3.32 & 4.32 \\
\hline
\end{tabular}

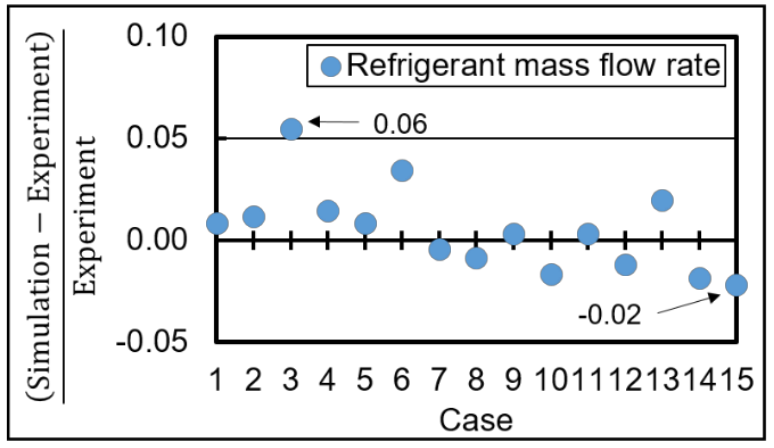

(a) Mass flow rate

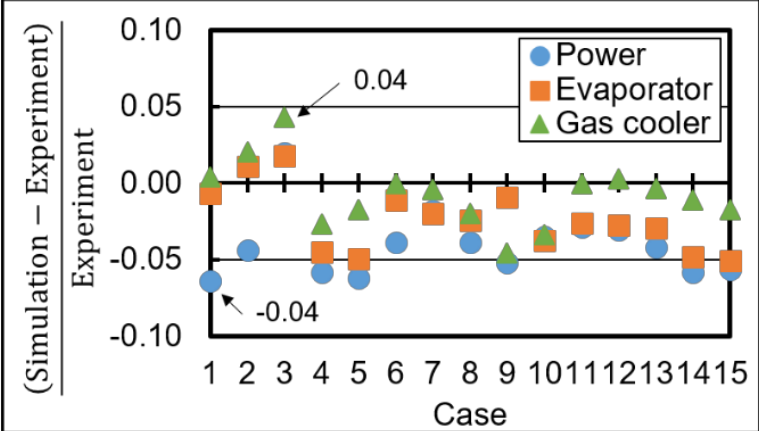

(b) Compressor power and capacity of HXs

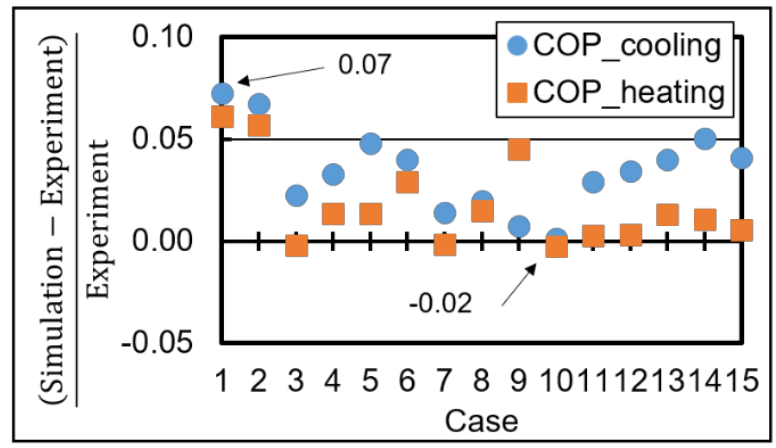

(c) $\mathrm{COP}$

Fig. 8: Comparison results; (a) refrigerant mass flow rate, (b) compressor power and capacity of each HX, (c) COPs. 


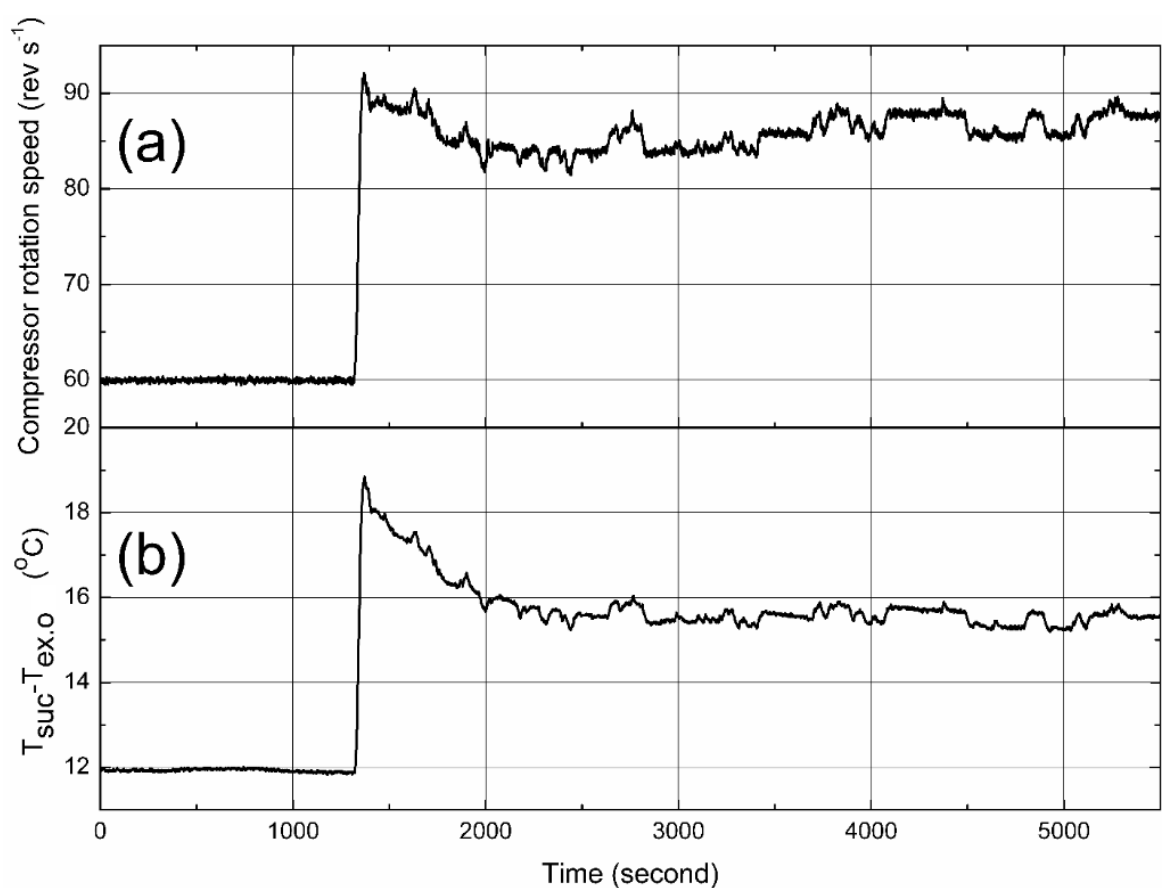

Fig. 9: Experiment when the compressor rotation speed step-up; (a) rotation speed, (b) temperature difference between at the suction and the EEV outlet.

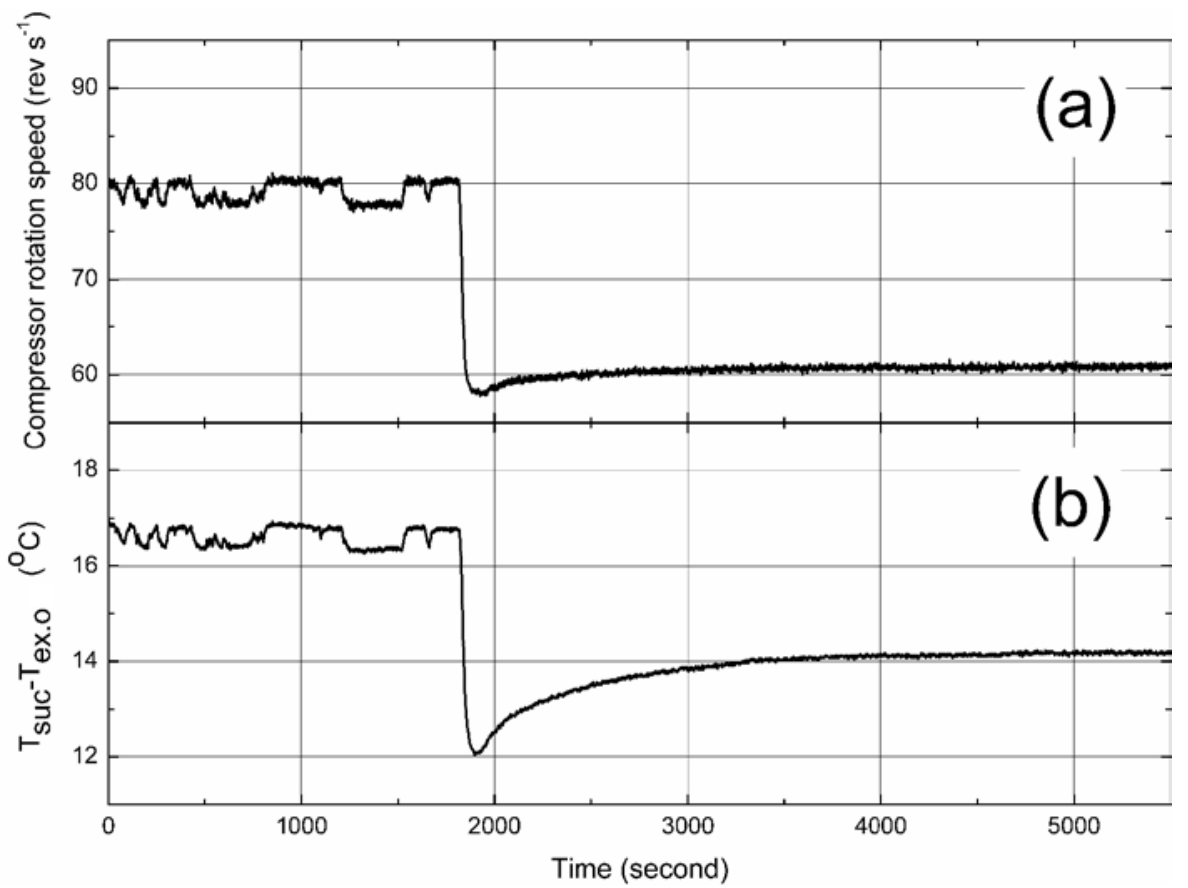

Fig. 10: Experiment when the compressor rotation speed step-down; (a) rotation speed, (b) temperature difference between at the suction and the EEV outlet.

\subsection{Transient performance}

In the case of transient conditions, experiments have been carried out with changing compressor rotation speed. Fig. 9 (a) depicts the experimental condition when the compressor rotation speed was suddenly increased from $60 \mathrm{rev} \mathrm{s}^{-1}$ to $87 \mathrm{rev} \mathrm{s}^{-1}$. During the experiment, the feed pump at the cooling water loop supplied the cooling water to the gas cooler with $128.7 \mathrm{~L} / \mathrm{h}$ of flow rate. The measured water temperature at the gas cooler inlet was
$30{ }^{\circ} \mathrm{C}$. The heating water was supplied to the evaporator with $99.9 \mathrm{~L} / \mathrm{h}$ of flow rate and the measured temperature was $20^{\circ} \mathrm{C}$ at the evaporator inlet. In each water loop, the flow rate of supplying water was kept constant and the measured water temperature at each $\mathrm{HX}$ inlet did not change during the experiment. Fig 9 (b) shows the measured temperature difference between the suction and the EEV outlet, $\left(T_{s u c}-T_{\text {ex.o }}\right)$, by the experimental EEV's opening. In the present simulation, the experimental 
compressor speed (Fig. 9 (a)) was used for the input value of the compressor model. The measured temperature difference (Fig. 9 (b)) was also used for the input value to the 'Control box Cross-section area' in the expansion device model (Fig. 3. (a)), as the target value of the temperature difference, $\left(T_{\text {suc }}-T_{\text {ex.o }}\right)_{\text {target }}$. The temperature of the thermal reservoir at the gas cooler model was set to $31{ }^{\circ} \mathrm{C}$ and the temperature of the thermal reservoir at the evaporator model was set to $8.3^{\circ} \mathrm{C}$. In the gas cooler, the input values of the refrigerant pressure and temperature were set to $7.7 \mathrm{MPa}$ and $32{ }^{\circ} \mathrm{C}$, respectively, while the input values of the refrigerant pressure and temperature were set to $4.5 \mathrm{MPa}$ and $11{ }^{\circ} \mathrm{C}$, respectively, in the evaporator.

Fig. 10 (a) shows the compressor rotation speed with time when the rotation speed was suddenly decreased from $80 \mathrm{rev} \mathrm{s}^{-1}$ to $60 \mathrm{rev} \mathrm{s}^{-1}$. In this experiment, the cooling water temperature at the gas cooler inlet was fixed to $30^{\circ} \mathrm{C}$ and the heating water temperature at the evaporator inlet was fixed to $20^{\circ} \mathrm{C}$. The feed pump in the cooling water loop supplied cooling water to the gas cooler with 129.6 $\mathrm{L} / \mathrm{h}$ of flow rate. In the heating water loop, the pump supplied heating water with $118.4 \mathrm{~L} / \mathrm{h}$ of flow rate. Fig. 10 (b) shows the measured temperature difference between the suction and the EEV outlet, $\left(T_{\text {suc }}-T_{\text {ex.o }}\right)$. As same as the case that the compressor speed suddenly increases, the measured compressor speed was used for the input value of the compressor model and the measured temperature difference was used for the input value for the target temperature difference, $\left(T_{\text {suc }}-T_{\text {ex.o }}\right)_{\text {target }}$, in the expansion device model. The temperature of the thermal reservoir at the gas cooler model was set to $29{ }^{\circ} \mathrm{C}$ and the temperature of the thermal reservoir at the evaporator model was set to $8.3^{\circ} \mathrm{C}$. In the gas cooler, the input values of the refrigerant pressure and temperature were set $7.9 \mathrm{MPa}$ and $32{ }^{\circ} \mathrm{C}$, respectively. The refrigerant pressure of $4.5 \mathrm{MPa}$ and the refrigerant temperature of $11{ }^{\circ} \mathrm{C}$ were input to the evaporator model.

The comparison results between the simulations and the experiments are described in Fig. 11 and Fig. 12. The results in Fig. 11 corresponds to the case when the compressor speed suddenly increases and, the results in Fig. 12 corresponds to the case when the compressor speed suddenly decreases, respectively.

As shown in Fig. 11 and Fig. 12, the comparison results show that the simulation model is a good agreement with the dynamic behavior of the experimental system and the corresponding performance change. However, there is a significant difference between the simulation and the experimental results in the gas cooler pressure and the heating capacity of the gas cooler, right after the compressor speed changes; this difference is commonly observed in Fig. 11 and Fig. 12. The corresponding simulation's results show an immediate response against the change, however, the corresponding experimental results show a gradual response against the change. This difference is mainly due to the compressor model. The present compressor model does not consider heat transfer between the compressor body and the ambient, and mechanical losses. During the compression process in an actual compressor, the input power does not fully contribute to increasing the refrigerant enthalpy, i.e., it is not fully utilized to the refrigerant's compression process. There is a loss of the part of the input power, therefore, it takes a significant time to supply the refrigerant with enough enthalpy. As shown in Fig. 11 (c and e) and Fig. 12 (c and e), the simulation results show that the calculated suction pressure and the cooling capacity at the evaporator are a good agreement with the response of the experimental system even though right after the compressor speed changes. This is because when the compressor speed changes in an actual system, the operating parameters in the low-pressure side of the system, such as the suction pressure, the suction temperature, and the suction flow rate immediately response to this change; therefore, the cooling capacity of the evaporator also responses this immediate change in an actual case. On the other hand, when the system becomes stable after the compressor speed changes, the simulation model recovers the prediction error within $\pm 7 \%$. 

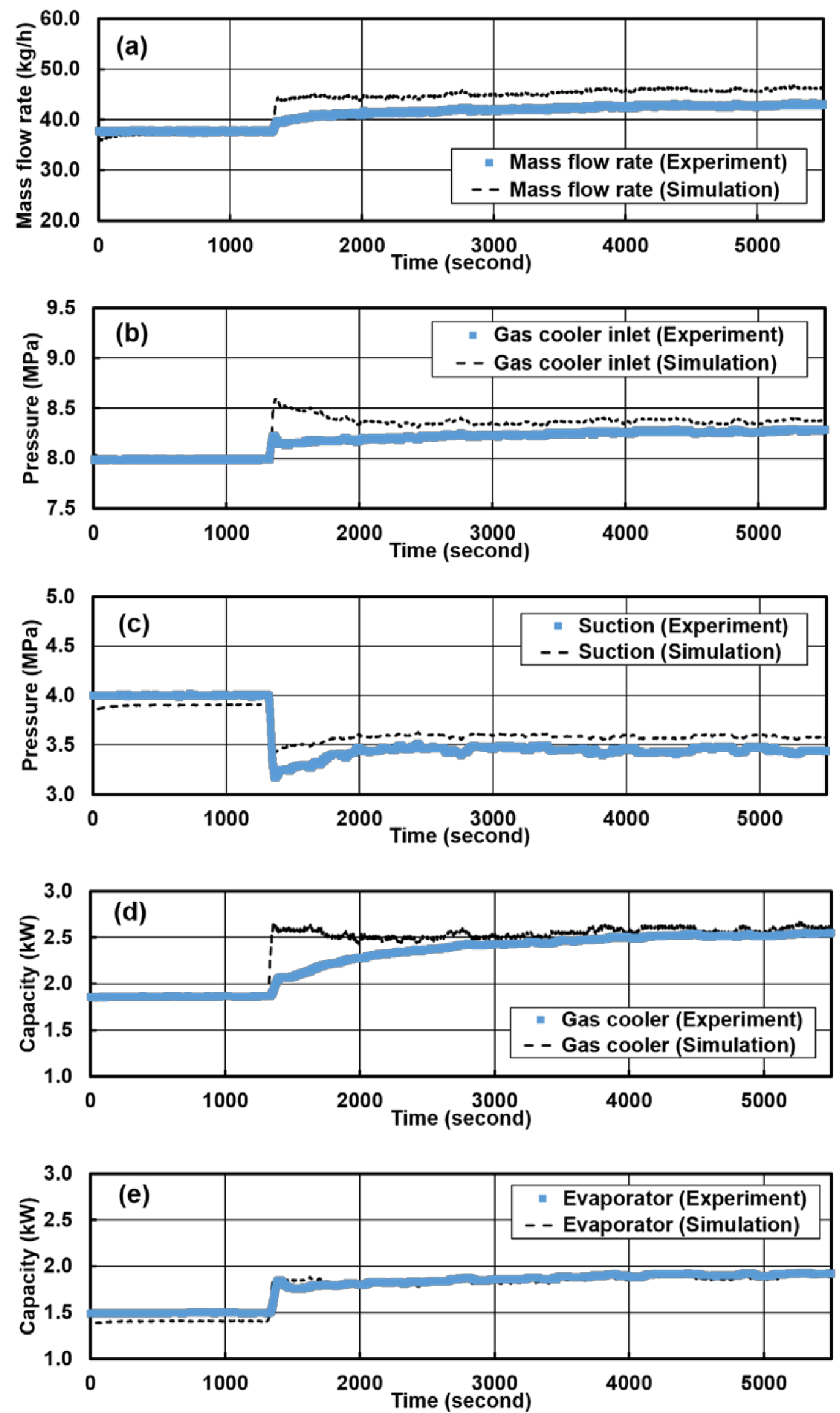

Fig. 11: Comparison results when the compressor rotation speed step-up; (a) refrigerant mass flow rate, (b) gas cooler inlet pressure, (c) suction pressure, (d) heating capacity, (e) cooling capacity. 

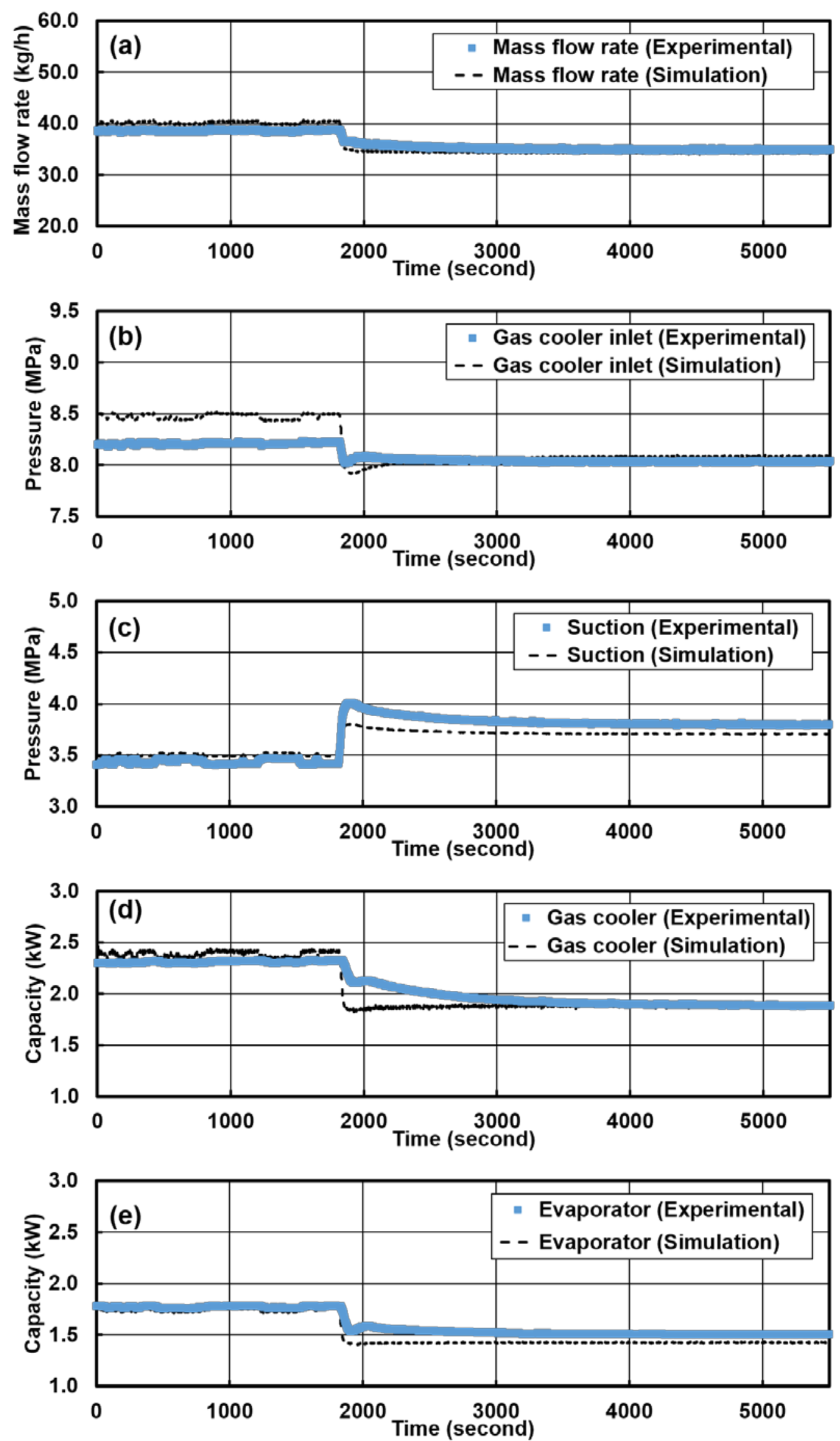

Fig. 12: Comparison results when the compressor rotation speed step-down; (a) refrigerant mass flow rate, (b) gas cooler inlet pressure, (c) suction pressure, (d) heating capacity, (e) cooling capacity. 


\section{Conclusion and limitations}

To develop smart-controlled thermal energy systems operated by real-time demand, it is key to understand the dynamic behaviors of the comprising devices; for that, pre-validated dynamic models are necessary. In the present study, a dynamic model for an R-744 transcritical heat pump system was developed utilizing the Simscape library. Using the model, simulations were conducted for both transient and steady-state conditions. Experiments were also conducted using R744 as a working fluid to validate the simulation model. The simulation results, such as refrigerant mass flow rate, cooling, and heating capacity, compressor power, and COPs were compared to that of the experimental data. The comparison results demonstrate that the simulation model can predict the performance of the actual system within $\pm 7 \%$ error in given steady-state conditions as well as the dynamic behavior of the actual system. However, a significant deviation from the experimental results was observed in the simulation results, when the compressor rotation speed changes. This is because the present compressor model does not take into account the effects of heat transfer with the ambient, and mechanical losses. For the improvement of the model, detailed compressor modeling will be required.

On the other hand, it is known that the heat transfer characteristic of R-744 abruptly changes in the transcritical region, since the thermophysical properties of R-744 changes dramatically near the pseudo-critical line. In the present gas cooler model established at the Simscape platform, the unit segment of the R-744 flow was set to the same size as the single tube of the experimental gas cooler. According to the validation results, the model shows decent prediction results in system-scaled performance and behavior, however, considering the set segment size, it will be difficult to follow up with the sudden change of the refrigerant heat transfer characteristic. This limitation may be solved by decreasing the segment size while this can cause an additional computational cost due to the increment in the number of segments. For improving the model, it is necessary that the size of the unit segment in gas cooler tubes are adjusted based on the sensitivity test of the segment size.

\section{Acknowledgments}

Not applicable.

\section{Nomenclature}

$\begin{array}{ll}\boldsymbol{A} & \text { heat transfer area }\left(\mathrm{m}^{2}\right) \\ \boldsymbol{A}_{\boldsymbol{c}} & \text { cross-section area }\left(\mathrm{m}^{2}\right) \\ \boldsymbol{B o}_{0} & \text { boiling number }(-) \\ \boldsymbol{C}_{\boldsymbol{D}} & \text { flow coefficient }(-) \\ \boldsymbol{C}_{\boldsymbol{P}} & \text { specific heat at constant pressure }\end{array}$

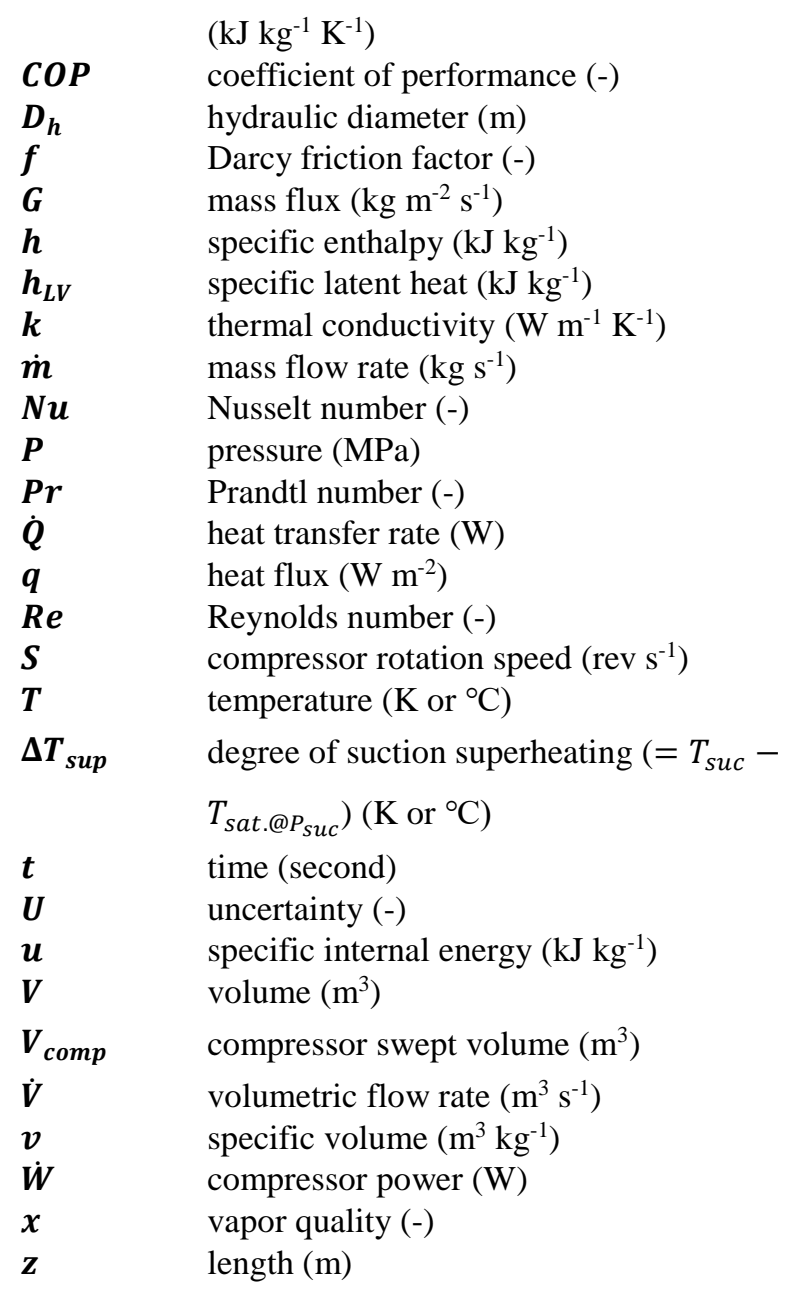

Greek symbols

$\begin{array}{ll}\boldsymbol{\Delta} & \text { difference } \\ \boldsymbol{\varepsilon} & \text { absolute roughness (m) } \\ \boldsymbol{\eta} & \text { efficiency }(-) \\ \boldsymbol{\zeta} & \text { property } \\ \boldsymbol{\lambda} & \text { heat transfer coefficient }\left(\mathrm{W} \mathrm{m}^{-2} \mathrm{~K}^{-1}\right) \\ \boldsymbol{\mu} & \text { dynamic viscosity (Pa s) } \\ \boldsymbol{\rho} & \text { density }\left(\mathrm{kg} \mathrm{m}^{3}\right) \\ \boldsymbol{\sigma} & \text { surface tension }\left(\mathrm{N} \mathrm{m}^{-1}\right) \\ \boldsymbol{\Psi} & \text { reduced data } \\ \boldsymbol{\psi} & \text { measured data }\end{array}$

\section{Subscripts}

$\begin{array}{ll}\mathbf{1} & \text { singe-phase } \\ \mathbf{2} & \text { two-phase } \\ \boldsymbol{c} & \text { cooling } \\ \text { cen } & \text { center } \\ \boldsymbol{d i s} & \text { discharge } \\ \text { evap } & \text { evaporator } \\ \boldsymbol{e x} & \text { expansion device } \\ \boldsymbol{e x p} & \text { experimental } \\ \boldsymbol{g} \boldsymbol{c} & \text { gas cooler } \\ \boldsymbol{i} & \text { inlet } \\ \boldsymbol{i n p u t} & \text { input } \\ \boldsymbol{L} & \text { saturated liquid state } \\ \boldsymbol{o} & \text { outlet }\end{array}$




$\begin{array}{ll}\text { ori } & \text { orifice } \\ \text { pred } & \text { prediction } \\ \boldsymbol{r} & \text { refrigerant } \\ \boldsymbol{s} & \text { isentropic } \\ \boldsymbol{r e s} & \text { thermal reservoir } \\ \text { suc } & \text { suction } \\ \text { sup } & \text { superheating } \\ \boldsymbol{V} & \text { saturated vapor state } \\ \boldsymbol{v} & \text { volumetric } \\ \boldsymbol{w} & \text { water } \\ \text { wall } & \text { tube wall }\end{array}$

\section{References}

1) H. Hui, Y. Ding, Q. Shi, F. Li, Y. Song, and J. Yan, "5G network-based Internet of Things for demand response in smart grid: A survey on application potential," Appl. Energy. 257113972 (2020). doi:https://doi.org/10.1016/j.apenergy.2019.113972.

2) S.A. Klein, J.A. Duffie, and W.A. Beckman, "TRNSYS - A transient simulation program," ASHRAE Trans. 82 (1) 623-633 (1976).

3) Modelica Association, "Modelica," https://www.modelica.org/ $1997 . \quad$ (accessed November 3, 2019).

4) Dassault Systemes ${ }^{\circledR}$, "Dymola: Dynamic Modeling Laboratory," https://www.3ds.com/productsservices/catia/products/dymola/ 2002. (accessed November 3, 2019).

5) MathWorks, "Simulink ${ }^{\circledR}$ User Guide 2018b," (2018).

6) MathWorks, "Simscape ${ }^{\mathrm{TM}}$ User Guide 2018b," (2018).

7) M. Wetter and C. Haugstetter, "Modelica versus TRNSYS - a comparison between an equation-based and a procedural modeling language for building energy simulation," Proc. 2nd SimBuild Conf. at Cambridge, MA, US. August 2-4, 2006. 262-269 (2006). doi:https://ibpsausa.org/index.php/ibpusa/article/view/220.

8) A. Elsheikh, E. Widl, P. Pensky, F. Dubisch, M. Brychta, D. Basciotti, and W. Muller, "Modelicaenabled rapid prototyping via TRNSYS," Proc. 13th Conf. Int. Build. Perform. Simul. Assoc. at Chambéry, France. August 26-28, 2013. 3291-3298 (2013). doi:http://www.ibpsa.org/proceedings/BS2013/p_14 14.pdf.

9) L. Giraud, R. Bavière, and C. Paulus, "Modeling of solar district heating: a comparison between TRNSYS and MODELICA," EuroSun2014, at Aixles-Bains, France, September 16-19, 2014 (2014). doi:https://doi.org/10.18086/eurosun.2014.19.06.

10) E. Atam, "Current software barriers to advanced model-based control design for energy-efficient buildings," Renew. Sustain. Energy Rev. 73 10311040

(2017). doi:https://doi.org/10.1016/j.rser.2017.02.015.

11) E. Jamila and S. Abdelmjid, "Physical Network
Approach Applied to Wind Turbine Modeling with Simscape Language," Open J. Model. Simul. 02 77-89 doi:https://doi.org/10.4236/ojmsi.2014.22010.

12) M. Trčka and J.L.M. Hensen, "Overview of HVAC system simulation," Autom. Constr. 19 93-99 (2010). doi:https://doi.org/10.1016/j.autcon.2009.11.019.

13) H. Qiao, V. Aute, and R. Radermacher, "Comparison of Equation-based and Non-equation-based Approaches for Transient Modeling of a Vapor Compression Cycle," Int. Refrig. Air Cond. Conf., at Purdue, West Lafayette, IN, US. July 16-19, 2012. 1205.

(2012). doi:https://docs.lib.purdue.edu/iracc/1205.

14) S. Singh and K. Sørensen, "Dynamic model of a heat pump based house heating system," Proc. 59th Conf. Simulation Model. (SIMS 59), at Oslo Metrop. Univ. Norw. September 26-28, 2018. 153 87-94 (2018). doi:https://doi.org/10.3384/ecp1815387.

15) A. Pal, K. Uddin, K. Thu, and B.B. Saha, "Environmental Assessment and Characteristics of Next Generation Refrigerants," Evergreen - Joint Journal of Novel Carbon Resource Sciences \& Green Asia Strategy, 5(2) 58-66 (2018).

16) T. Pfafferott and G. Schmitz, "Modelling and transient simulation of $\mathrm{CO}_{2}$-refrigeration systems with Modelica," Int. J. Refrig. 27 42-52 (2004). doi:https://doi.org/10.1016/S0140-007(03)00098-7.

17) R. Shi, D. Fu, Y. Feng, J. Fan, and S. Mijanovic, "Dynamic Modeling of CO2 Supermarket Refrigeration System," Int. Refrig. Air Cond. Conf. at Purdue, West Lafayette, IN, US. July 12-15, 2010. 1127 doi:http://docs.lib.purdue.edu/iracc/1127.

(2010).

18) L. Zheng, J. Deng, Y. He, and P. Jiang, "Dynamic model of a transcritical $\mathrm{CO}_{2}$ ejector expansion refrigeration system," Int. J. Refrig. 60 247-260 (2015). doi:https://doi.org/10.1016/j.ijrefrig.2015.08.019.

19) L. Zheng, J. Deng, and Z. Zhang, "Dynamic simulation of an improved transcritical $\mathrm{CO}_{2}$ ejector expansion refrigeration cycle," Energy Convers. Manag. $114 \quad 278-289 \quad$ (2016). doi:https://doi.org/10.1016/j.enconman.2016.01.069.

20) J. Bush, V, Aute, and R, Radermacher, "Transient simulation of carbon dioxide booster refrigeration system with mechanical subcooler in demand response operation," Sci. Technol. Built. En. 24(7) 687-699 doi:https://www.tandfonline.com/doi/full/10.1080/2 3744731.2017.1419733.

21) E.W. Lemmon, I.H. Bell, M.L. Huber, and M.O. McLinden, "REFPROP; Reference Fluid Thermodynamic and Transport Properties version 10.0," NIST Standard Reference Database 23, (2018).

22) MathWorks, "Simscape ${ }^{\mathrm{TM}}$ Reference 2018b," (2018). 
23) J.M. Winkler, "Development of a component based simulation tool for the steady state and transient analysis of vapor compression systems (Doctoral dissertation)," Department of Mechanical Engineering, University of Maryland College Park, MD. USA (2009). doi: https://drum.lib.umd.edu/handle/1903/9493.

24) G.L. Ding, "Recent developments in simulation techniques for vapor-compression refrigeration systems," Int. J. Refrig. 18 1119-1133 (2007). doi: https://doi.org/10.1016/j.ijrefrig.2007.02.001.

25) S.E. Haaland, "Simple and explicit formulas for the friction-factor in turbulent pipe flow," J. Fluids Eng. 105(1) 89-90

(1983). https://doi.org/10.1115/1.3240948.

26) V. Gnielinski, "New equations for heat and mass transfer in turbulent pipe and channel flow," Int. Chem. Eng. 16 359-368 (1976).

27) X. Fang, "A new correlation of flow boiling heat transfer coefficients for carbon dioxide," Int. J. Heat Mass Transf. $64 \quad 802-807 \quad$ (2013). doi:https://doi.org/10.1016/j.ijheatmasstransfer.201 3.05.024.

28) T.L. Bergman, A.S. Lavine, F.P. Incropera, and D.P. Dewitt, "Fundamentals of heat and mass transfer," 7th edition, John Wiley and Sons, 2011.

29) J.M. Yin, C.W. Bullard, and P.S. Hrnjak, "R-744 gas cooler model development and validation," Int. J. Refrig. $24 \quad 692-701 \quad$ (2001). doi:https://doi.org/10.1016/S0140-7007(00)000827.

30) R. Rieberer, "CO $\mathrm{CO}_{2}$ properties," IIR Workshop on $\mathrm{CO}_{2}$ Technology in Refrigeration, Heat Pump and Air Conditioning Systems at Mainz, Germany. 1999. (1999).

31) J. Pettersen, R. Rieberer, and A. Leister, "Heat transfer and pressure drop characteristics of supercritical carbon dioxide in microchannel tubes under cooling." Proc. of 4th IIR Gustav Lorentzen Conf. on Natural Working Fluids at Purdue, West Lafayette, IN, US. July 25-28, 2000. 99-106 (2000). 